\title{
MODELS OF LAW
}

Christian Turner ${ }^{*}$

\begin{abstract}
The more we examine what is behind our most difficult legal questions, the more puzzling it can seem that we continue both to disagree strongly and, yet, to cooperate. If law is a reasoned enterprise, how is it that we are neither torn apart nor homogenized by our long social practice of it? I resolve this puzzle, and arrive at a richer understanding of law, using the idea of modeling familiar from the natural sciences and mathematics. I show (a) that theorists can model legal systems as abstract systems of institutions, information flows, and institutional processing or reasoning and (b) that the participants in a legal system themselves maintain and evaluate models of this sort. Understanding law this way clarifies numerous problems ranging from pluralism to legal interpretation. This work emphasizes four major points of the theory:

(1) It identifies law as the conceptual side of cooperation and, thus, the means of coordinating decisionmaking.

(2) It derives from human cooperation a picture of legal systems as a network of institutions exchanging information and maintaining their own rules of recognition and decision.

(3) It advances the thesis that cooperation and its associated legal system arise when individuals create institution-information models, identify the models used by others, and accept the use of those models.

(4) Finally, it provides a standard representation of institutions, their communications, and their reasoning. This analysis reveals that institutional agreement and disagreement occur at discrete levels.

Together, these elements yield a theory of legal systems that grounds jurisprudence in the study of the human conceptual system. It sheds new light on the problem of theoretical disagreement, otherwise puzzling problems of pluralism, and the connection between law and morality.
\end{abstract}

\footnotetext{
* Associate Professor, University of Georgia School of Law. For helping this Article along its long path, I thank the participants at the 2015 UGA-Emory Faculty Colloquium, especially Liza Vertinsky; the attendees of the 2014 conference of the Association of Law, Property, and Society at the University of British Columbia; the social scientists, economists, and philosophers who expanded my mind considerably at the Third WINIR Conference: Institutions and Human Behavior; the faculty attending the University of Queensland T.C. Berne School of Law's Research Seminar, especially the feedback and follow-up from Graeme Orr and Kit Barker; and the participants at the 2014 conference of the Law and Society Association of Australia and New Zealand. Special thanks to Christopher Elmendorf, Gregory Klass, Michael Madison, Joseph Miller, Usha Rodrigues, and Brian Tamanaha for reading earlier drafts and making key suggestions. Also, one more thank-you to Joseph Miller for, correctly, convincing me to cut my favorite scene. I am forever indebted to the research assistance of Michael Aune, Charles Spalding, Sam Weaver, Sterling Waite, Gregg Jacobson, Hunter Carpenter, Brian Stoltz, and Matthew Traut.
} 


\section{CONTENTS}

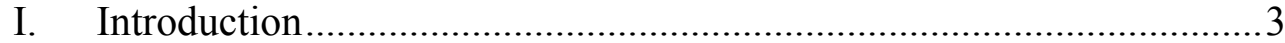

A. The Fact of Legal Disagreement ................................................... 3

B. A "Non-Legal" Example..............................................................6

C. A Way Forward......................................................................... 9

II. The Identity Framework ........................................................... 12

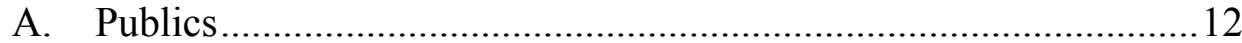

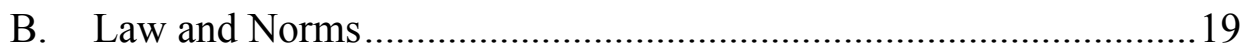

III. The Modeling Thesis ................................................................... 21

A. Why Models? ..........................................................................21

B. Mental Models and Object-Orientation .......................................26

C. Law as Object-Oriented Modeling.............................................28

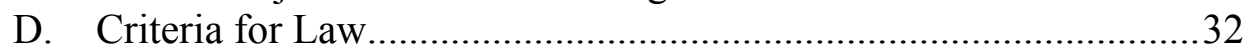

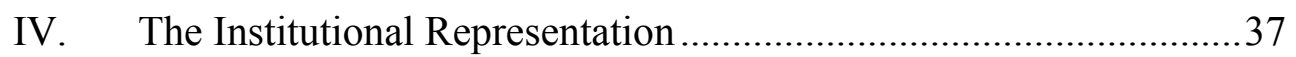

A. The General Model of Information Flow Through a Decisionmaking

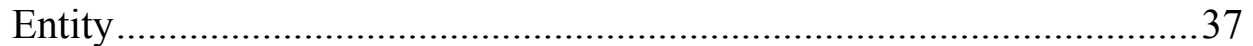

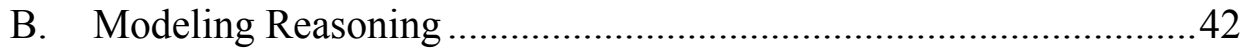

C. A Model of Rules in an Institutional Setting ................................48

D. The Monopoly Example .........................................................58

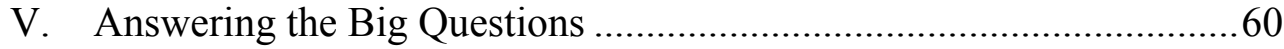

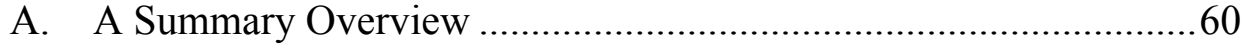

B. The Traditional Questions of Jurisprudence ....................................61

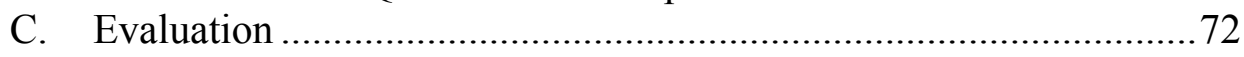

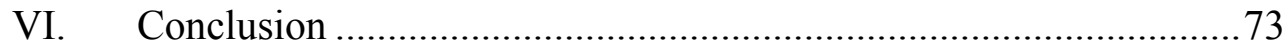




\section{INTRODUCTION}

\section{A. The Fact of Legal Disagreement}

After the death of Justice Scalia, Senate Majority Leader Mitch McConnell and other Republican leaders stated that they would not consider any Supreme Court nominations made by President Obama. ${ }^{1}$ McConnell argued that the appointment would be highly consequential and therefore best made after the looming election, by the people's choice for the next President. Is this position legal or legitimate?

The Constitution, in a section granting powers to the President, states that the President "shall nominate, and by and with the advice and consent of the Senate, shall appoint ... judges of the Supreme Court." 2 This clause is susceptible to many interpretations as its words are bent toward application. Perhaps it permits the Senate to refuse henceforth to hold hearings on any Supreme Court nominees, leaving plenary power in the Senate to decide how to advise and whether to consent. The actual words, one might argue, create no obligation for the Senate to consider a nomination, and the words are the end of the matter.

What should we make, then, of the words that tells us that the President "shall appoint" "by and with the advice and consent of the Senate"? This instruction seems incompatible with a decision by the Senate to refuse to advise or even to consider consenting. Moreover, it seems odd that a single subinstitution of the federal government could, through steadfast inaction, cause there to be no judges at all left in the judiciary. Indeed, other words of the Constitution appear to assume that there will be a Supreme Court and therefore at least one federal judge: "The judicial power of the United States, shall be vested in one Supreme Court ...."3

Reliance on words as authority or as the full embodiment of others' authority runs into another problem. They often fail to capture the real limits of what we are willing to accept. For example, the Constitution grants to Con-

\footnotetext{
${ }^{1}$ David M. Herszenhorn, G.O.P Senators Say Obama Supreme Court Pick Will Be Rejected, N.Y. TiMES (Feb. 23, 2016) (http://www.nytimes.com/2016/02/24/us/politics/supreme-court-nominationobama.html).

${ }^{2}$ U.S. Const. art. II, $\S 2$.

${ }^{3}$ U.S. Const. art. III, $\S 1$.
} 
gress the power to impeach and remove from office the President, Vice President, and "all civil officers of the United States." Would Congress have the power under this clause to remove from office the President, Vice President, all cabinet members, and the entire bench of the Supreme Court? The Speaker of the House would become president, ${ }^{4}$ and the entire Supreme Court and cabinet could then be appointed, perhaps from Congress' own ranks. If the Supreme Court has the ultimate power "to say what the law is," would the new Justices be permitted to interpret the Constitution not to require further elections? If that is a "wrong" interpretation, what is the constitutional remedy?

Any reader of this article is more than able to construct the obvious and decent arguments on all sides of the above questions. The language, logic, and rhetorical form of such arguments are not difficult to grasp. That's not the problem. What makes selecting among legal solutions difficult, rather, is that there is no conceivable way to prove that any one of them is correct. There just is no uncontroversial theory of truth in law. While correctness is always and ultimately relative to an authority, there may not be agreement on what gives a rule its authority. What warrant is there for telling Mitch McConnell that he is wrong, that your criticism of his position reflects something other than a difference of opinion or of premises? ${ }^{6}$

Every legal statement concerns what some other person should do in the social context in which the legal system arises. A person should pay a fine. A judge should use some statutory text to make a decision. A jailor should confine a person designated as a prisoner. The Senate should hold confirmation hearings. Each of these statements about what others should do is obviously moored to other suppositions concerning social obligations - that word, "should," carrying an implication that other truths underwrite the truth of the assertion itself. The judge is bound by constitutional legislative action. The jailor should follow orders of particular courts. The Senate is restrained and empowered by the Constitution. It is only within the context of such sets of supposed further truths that the isolated truth or falsity of the statement follows.

When we disagree about what the law requires, or what we should do, our disagreement must either be in competing premises, those other truths that operate both ultimately and interstitially, or in an error one of us has

\footnotetext{
${ }^{4} 3$ U.S.C. § 19(a)(1). But see Akhil Reed Amar and Vikram David Amar, Is the Presidential Succession Law Constitutional?, 48 StAN. L. Rev. 113 (1995) (arguing that the Constitution's text, history, and structure should be read to forbid designation of federal legislators in the line of succession).

${ }^{5}$ Marbury v. Madison, 5 U.S. 137, 177 (1803).

${ }^{6} \mathrm{We}$ have in law yet another version of the major puzzle of human social organization: "The big question for scholars of ideas is why some ideas become the policies, programs, and philosophies that dominate political reality while others do not." Vivien A. Schmidt, Discursive Institutionalism: The Explanatory Power of Ideas and Discourse, 11 AnN. REV. POL. SCI. 303, 307 (2008).
} 
made in reasoning with them. Sound logic, dialogue, and training might be expected to decrease the incidence of the latter. The beast, though, lies in the former, finding that our disagreement stems from divergent premises, from different truth metrics. From such disagreements are launched thousands of volleys charging illegitimacy, judicial activism, tyranny, and mundane unreasonableness.

One might hope that we could just be clear about premises. We may hope that we could uncontroversially identify an agreed-upon set of starting points and interstitial glue, whether by studying the meaning of the word "law," consulting religious texts, discovering the truth of natural axioms, or even designating by fiat a particular text as ultimately authoritative. But our disagreement concerning the rules of the game reflects deeper disagreement concerning what the game is, revealing disparate attitudes toward and interpretations of these supposedly axiomatic texts, doctrines, and ideas. ${ }^{7}$ Minds can never truly and completely meet, because no mind is ever complete in its understanding of social reality. Our assessments and attitudes unfold. These attitudes simply cannot be corralled by any ultimate logic. Their genesis and evolution are in human minds, and they respond to the reality of lived experience, the collision of new problems with the old utterances. ${ }^{8}$

I will argue that what we conventionally call law is just the conceptual side of cooperation. Every instance of human cooperation yields an explicit or implicit legal system governing that cooperation. This resulting legal system only exists, moment by moment, in the minds of participants as a capacity to generate mental models of the cooperation itself. The system is perceived as law by a participant when she accepts the models of the cooperation she identifies others as using. Further, we can describe these models as networked institutions exchanging information according to the institutions' internally maintained program for decisionmaking. Models of law exist in participants' minds at many scales, from whole governments to more detailed models of legislatures or courts to contracting parties to families. They are generated on demand to answer questions about the cooperation. As I will discuss, our mental experience of cooperation, and thus law, is not substantially different in this respect from our other experiences in life.

\footnotetext{
${ }^{7}$ RONALD DwORKIN, LAW's EMPIRE 238 (1986) (Dworkin, in his famous chain-novel analogy compares the legal enterprise to literary criticism and notes that a critic of your conviction concerning how the next chapter of a book should unfold may "not [be arguing] that he thinks you should respect the text, while you think you are free to ignore it. Your disagreement is more interesting: you disagree about what respecting this text means.").

${ }^{8}$ See, e.g., H.L.A. HART, THE CONCEPT OF LAW 128 (2nd ed. 1994) (“[W]e are men, not gods. It is a feature of the human predicament (and so of the legislative one) that we labour under two connected handicaps whenever we seek to regulate, unambiguously and in advance, some sphere of conduct by means of general standards to be used without further official direction on particular occasions. The first handicap is our relative ignorance of fact: the second is our relative indeterminacy of aim.”).
} 
This idea, that law is the adaptive, mental modeling of cooperation, is what I call the modeling theory of law. It would be surprising if jurisprudence could be anything but theorizing and studying the way human minds perceive legal systems. Being clear about this will orient legal theory toward the study of minds themselves. While the modeling theory of law helps make sense of traditional but persistent problems in legal theory, it also poses dramatic new questions for jurisprudence that point the way toward a possible cognitive science of law that would aim to increase our knowledge of how people perceive, evaluate, and transmit regulatory information. A science of the phenomenon of law is the future of jurisprudence, law as itself a metaphysical science its past.

\section{B. A "Non-Legal" Example}

An example helps build the intuitions I hope to reward in the analysis that follows. Many legal philosophical treatments use the playing of games as an instructive analogue to legal systems. ${ }^{9}$ As will become apparent, I view the playing of games, like all other instances of cooperation, as generative of legal systems. The continuity or separateness of "game" systems from other legal systems is a property of the models of the respective systems their participants maintain and, thus, a matter of social convention rather than ontology. ${ }^{10}$ So let us consider a friendly game of Monopoly.

Without saying much more about their reasons for doing so, three friends take Monopoly off the shelf, open the box, unfold the board, set up the cards, cash, and pieces, and begin to play. A few turns in, one player lands on States Avenue and announces that she does not wish to buy it. The next player then picks up the dice but is interrupted by the third, who tells the others they are forgetting to hold the auction.

\footnotetext{
${ }^{9}$ See e.g., HART, supra note 8, at 142-45 (arguing that rules are law are not merely whatever courts say they are just as the rules of an officiated game do not reduce to whatever a referee says they are); Scott Hershovitz, The End of Jurisprudence, 124 YALE L.J. 1160, 1181-86 (2015) (analyzing the origin of normativity of officially sanctioned rules of chess).

${ }^{10}$ Here, as I discuss further in Part V, I agree with Brian Tamanaha's argument that "law is whatever people identify and treat through their social practices as 'law." BRIAN TAMANAHA, A GENERAL JURISPRUDENCE OF LAW AND SOCIETY 166 (2001). But I agree with him in two specific senses I believe compatible with his thesis: (1) The set of practices a society would call its "law" is identified by a social, conventional practice of mutual categorization. (2) The more general usage of "law," the one I argue here is universal and which does not rely on a self-conscious societal labeling as such, is also socially constructed, arising from cooperation and the acceptance of the models participants identify as being used by others. This is the process that results in a society's "identify[ing]" and "treat[ing]" physical behaviors in the world-writing judgments, voting on legislation, and arguing at a trial, for example-as part of a social construct we can call law. See Part III, infra.
} 
"I'm sorry. The what?" comes the response. "Yeah, when you land on an unowned property but you don't want to buy it, the property's auctioned off to the highest bidder."

"Ok... that's not the way we've ever played. Sounds weird."

"Those are the rules. I know a lot of people don't know about it. But look." The third player then picks up the yellowing instruction booklet and turns to page four:

Whenever you land on an unowned property you may buy that property from the Bank at its printed price. You receive the Title Deed card showing ownership; place it faceup in front of you.

If you do not wish to buy the property, the Banker sells it at auction to the highest bidder. The buyer pays the Bank the amount of the bid in cash and receives the Title Deed card for that property. Any player, including the one who declined the option to buy it at the printed price, may bid. Bidding may start at any price. ${ }^{11}$

The other two players tell the third that, whatever might be printed in the rules, that is not how anyone they know has ever played Monopoly. And it's not how they intend to play this game.

Each participant now has several things to think about. First, each might think about how the game ought to go, in light of its purpose, under the two possible rules. Which rule would make the game more fun, faster, more leisurely, less antagonistic, more competitive, fairer, easier, harder, more official? Each could, in other words, evaluate the rules directly for their desirability. Of course, the players might fundamentally disagree on what makes a rule desirable and on how the two rules under consideration would affect those desiderata. They could, thusly, disagree at a level of theory or of practice, reaching in either way different conclusions regarding how to play the game.

Their thinking about these rules could, however, occur on a level above such direct analysis. Who should make the decision about the rule? The possibilities here include the game's original makers, the publishers of this edition, some notion of the general public practice, whatever a majority of them decides would be most desirable, whatever a majority decides but only if each is genuinely attempting to interpret the written rules rather than to replace them, whatever the owner of the house in which they're playing wants to do, whatever the owner of the board game wants to do, whatever the player most on the verge of quitting the game wants to do, and so on.

\footnotetext{
${ }^{11}$ Hasbro Corp., Monopoly: Property Trading Game from Parker Brothers at 4, available at http://www.hasbro.com/common/instruct/00009.pdf.
} 
At a still higher level of thinking, each would consider what reason he or she has to select the reason that will dictate who decides what the rule is: the pursuit of pure fun, the recognition of a least ambiguous source to promote coordination, that hosting is an imposition and sociality is otherwise promoted by giving authority to hosts, that their continued relationships will be better if they just vote and get on with it. Our players are considering models of cooperative decisionmaking that involve different institutional actors transmitting information and different rules to be used to evaluate that information.

Whatever rules they choose and even if they change their minds midgame, their game continues. Sure, an observer could snark that they are not "really" playing Monopoly. Fair enough, but what that person cannot say is that they are not playing a game. What is it that allows the players to do so? And on what grounds could a player tell the others they are "doing it wrong," not just undesirably?

If cooperation continues, so too does this legal system. Each player is accepting the model of rules they think is being used by the others. Those accepted models may be incomplete and even at odds with one another. Indeed, each player has in mind not so much an encyclopedic list of rules, but rather a capacity on demand to produce rules and evaluate rules announced by others. Players maintain, generate, and evaluate models of their cooperation at scales relevant to the issues that arise. For example, it is possible they agree at the inception to "play the game," by which they all mean "to play in conformity with "the rules." And by "the rules" they mean what they believe the instructions to mean for their game. They each believe that the others have such a model in mind, and they cooperate on that basis. Whether the refinements and applications of these models that occur as controversies arise will result in the players' discontinuing their cooperation depends on the judgments of each as play evolves. Their initial, naïve assumptions might be challenged by new facts that unearth formerly tacit commitments: to fun and friendship, perhaps. The cooperation, and thus the legal system among them that is quietly giving shape to that cooperation, may continue or disintegrate when one of them invokes the auction rule or when another proposes allowing a five-year-old to join and to move however many spaces are reflected by her five-year-old, rampaging id, without regard to dice. Their agreements and disagreements can occur at the level of fact, rule, identification of rulemaker, or theory for identifying rulemaker. ${ }^{12}$

What really distinguishes our Monopoly game and the game underfoot in the Senate? Yes, different sorts of decisions are being made; different consequences are possible; different motivations may be found in participants.

\footnotetext{
${ }^{12}$ See Part IV(C), infra (discussing more rigorously these levels of agreement and disagreement).
} 
While the models of institutions and reasons that Senators maintain and generate, the ones that create the reality of cooperation in their minds, take account of different facts and values and involve different sources of information than do those of our Monopoly players, the basic process is the same. Modeling and acceptance are what form the internal, conceptual reality of cooperation.

\section{A Way Forward}

Thinking about constitutional disagreements alongside those of boardgame players is one of the more visceral ways to consider the problem of disagreement in law. Does a political opponent's understanding of the appropriate reasons for institutional action, those reasons that lead her to argue that the Senate can do this or cannot do that, have the stability and fidelity to some principle, at some level of generality, that would cause you to accept it as legitimate, even if you disagree with her conclusion or even with her starting points? What deviations from your understanding of the right rules of Monopoly or of the manner in which friends should play board games would you tolerate? Introspection suggests that when we cooperate we are often taking account of others' reasons and perspectives, not simply calculating for each possible action we might take the probabilities that our fellow participants will inflict harms on us. ${ }^{13}$

This sort of question, whether you accept the model of social reality that is implicit in an argument another makes about the terms of your cooperation, is the one that points the way to a deeper, more accurate, and more rigorous understanding of legal systems. More to the point: now that we are all legal realists and now that we acknowledge that there does not exist even the potential of an authoritative text that could definitively answer all legal questions, ${ }^{14}$ how are agreement and coherent disagreement still possible within the ordinary language of law? The answer lies in candidly acknowledging our

\footnotetext{
${ }^{13}$ For Oliver Wendell Holmes, legal duties were "nothing but a prediction that if a man does or omits certain things he will be made to suffer in this or that way by judgment of the court." Oliver Wendell Holmes, Jr., The Path of the Law, 10 HARV. L. REV. 457, 458 (1897). Holmes was as beautiful a thinker as he was a writer. While he argued that the laws could be externally described by potential, authoritative resolutions of disputes, the sharp end of the public's stick, and thus doing the law amounted to predicting the same, he did not suggest that the task of prediction, much less construction, was divorced from understanding others' reasons. "If you want to know the law and nothing else, you must look at it as a bad man, who cares only for the material consequences which such knowledge enables him to predict, not as a good one, who finds his reasons for conduct, whether inside the law or outside of it, in the vaguer sanctions of conscience." Id. at 459 (emphasis added).

${ }^{14}$ Laura Kalman, Legal Realism at Yale, 1927-1960 229 (1986); Joseph William Singer, Legal Realism Now, 76 CAL. L. REV. 465, 465 (1988).
} 
continuous modeling and simulation of our social circumstances, not pretending no such models exist or that there is only one.

Positivists have argued that law is a system of authoritative guidance, the existence and content of which can be identified by social facts alone. ${ }^{15}$ But they have been criticized for not adequately explaining why law, so understood, should obligate anyone to follow it. ${ }^{16}$ And their efforts to explain radical disagreement about law's content have not fully been resolved. ${ }^{17}$ Natural lawyers, in contrast, point to an objective law derived from our study of the nature of human beings or from moral philosophy, ${ }^{18}$ but they do not so much explain the phenomenon of cooperative systems as define an ideal category. They can assert that such ideal law should be followed but do not give credible accounts of valid but theoretical disagreement in pluralistic societies. We need a new starting point that appreciates that law is a product of human cognition in a social setting. ${ }^{19}$ The goal should be to understand the cooperative behaviors we call law in a way that makes sense of the fact that people disagree about what the law should be, what it is, and whether there is an obligation of some kind to follow it.

This Article advances a theory of what we are doing when we do law that (a) characterizes the concept of law as inevitably joined to the fact of cooperation, (b) locates that phenomenon in the physical activities of separate minds, (c) helps make sense of the fact of legal agreement and disagreement, and (d) lays the groundwork for more sophisticated, accurate, and necessarily interdisciplinary modeling of the evolution of legal systems.

I construct this theory in discrete parts:

- the Identity Framework, an understanding of law and cooperation as conceptually bound to one another;

- the Institutions and Information Model, a description of an instance of such cooperation;

\footnotetext{
${ }^{15}$ See, e.g., Scott J. Shapiro, Legality 27-28 (2011) (defining positivism and distinguishing it from natural law).

${ }^{16}$ See LON L. Fuller, The Morality of Law 38-41 (1969) (arguing that an obligation of fidelity to law arises only under systems that observe basic moral tenets of good rule-making); see also John Finnis, Law and What I Truly Should Decide, 48 AM. J. OF JuRIS. 107, 115 (2003) ("[A] complete and fully realistic theory of law can be and in all essentials has been worked out from the starting point of the one hundred percent normative question, what should I decide to do and, equivalently, what kind of person should I resolve or allow myself to be.")

${ }^{17}$ See, e.g., Scott J. Shapiro, The "Hart-Dworkin" Debate: A Short Guide for the Perplexed, in Ronald Dworkin 40-41 (Arthur Ripstein ed.) (2007) (giving a crisp and lucid summary of Dworkin's attack on positivism from theoretical disagreement).

${ }^{18}$ See, e.g., Randy E. Barnett, A Law Professor's Guide to Natural Law and Natural Rights, HARV. J.L. \& PUB. POL'Y, 20 659-66 (1997) (characterizing natural law as resting on arguments of the form: "Given facts about human nature and the nature of the world . . , if you want to accomplish certain ends, then you should do $X$." (emphasis in original)).

${ }^{19}$ Cf. Oliver Wendell Holmes, JR., The COMmon Law 1 (1881) ("The life of the law has not been logic: it has been experience.").
} 
- the Modeling Thesis, asserting that law and cooperation arise from individual acts of modeling and of evaluation of such models;

- $\quad$ and the Institutional Representation, a standard language to describe institutional connections and reasoning.

First, in Part II, I define a framework under which law is understood as the conceptual side of cooperation. When we attempt to understand a group's law, we aim to understand the conditions of its cooperation, whether the cooperation itself and those conditions are implicit or explicit. So understood, cooperation and law are two sides of the same phenomenon, like mass is to gravity. An instance of cooperation entails the existence of legal system, even if only implicit, and to identify a legal system is to identify cooperating decisionmakers. I label this claim the Identity Framework.

This move dispenses with the distracting and, I argue, illusory problem of distinguishing law from other norm-thick but "unofficial" group activities. And it will allow us to make sense of the connection between moral principles and legal principles.

Once the problem of law is understood as describing how human beings conceive of their cooperation, we will become interested in the management within the mind of social complexity. In particular, I describe the organization of legal systems into public and private information-exchanging institutions. Legal systems, whether traditional or not, can be modeled as a collection of such institutions. I call this the Institutions and Information Model of legal systems, and I argue that it arises naturally from the Identity Framework.

In Part III, I advance the Modeling Thesis that law itself (and, therefore, cooperation) arises from individual acts of modeling. Law is social reality perceived and, thus, modeled. Our perception of law is a compound process of identifying the models of cooperation used by others, constructing our own models, and experiencing attitudes arising from the simulation of real and imagined inputs to those models. Cooperation, from the internal point of view of an individual, amounts to accepting models one perceives as describing the participation and decisionmaking of others. This understanding leads to specific, cognitively grounded criteria for law.

In the fourth Part, I develop a common language, the Institutional Representation, for the mental models people maintain about cooperation. I describe legal systems as systems of information-connected, decisionmaking institutions. Each such modeled institution (a) receives inputs from other institutions, (b) processes those inputs according to sets of reasons, and (c) produces informational output. Institutions within a modeled legal system maintain their own sets of reasons for decisionmaking, those reasons terminating in a local, ultimate rule of recognition. And institutions are stitched together 
into system because they each possess rules that take account of the information produced by other institutions. The structure of rules in such models can be analyzed in terms of discrete levels, as in our Monopoly example above.

In Part V, I briefly survey how the modeling theory of legal systems confronts the traditional questions of jurisprudence, including how laws are identified, how identification rules avoid infinite recursion, the source of law's normativity, the relation of law to morality, and the problem of interpretation.

Ultimately, the modeling theory of legal systems stakes out a jurisprudential claim but does not fit comfortably within any of the dominant genres of theories of law. While it is indeed fundamentally positivist, identifying the existence of law and law's content with acts of mental modeling, it does not suppose there must exist a system of identifiable rules and is fully compatible with radical indeterminism. It acknowledges the problem of theoretical disagreement, but it is not interpretivist and does not suppose legal questions have single right answers. And it certainly does not depend on there being any inalterable rules that would underwrite the rest of a legal system. This is not a theory of natural law. It is, rather, a suggestion that if understanding cooperation is what we are ultimately after, then we must understand cooperation.

\section{THE IDENTITY FRAMEWORK}

Let us establish first that the perception of a legal system is identical to the perception of cooperation. Human cooperation instantiates a legal system, and to observe a legal system is to observe cooperation. ${ }^{20}$ This will reveal that the struggle to distinguish law from not-law is often better understood as an effort to distinguish instances of cooperation from one another on conventional grounds, rather than on the basis of truly fundamental, ontological differences.

\section{A. Publics}

When people cooperate, they become more than a collection of individuals. Cooperation entails coordination of not just action, but decisionmaking.

\footnotetext{
${ }^{20}$ See Christian Turner, Origins of the Public/Private Theory of Legal Systems, in Private LAw: KeY Encounters with Public LaW 117, 120-22 (Kit Barker and Darryn Jensen, eds., Cambridge University Press, 2014).
} 
People and some other animals cooperate, ${ }^{21}$ but rocks do not, even if we recognize that the past and future of a rock in a scree field depends on the movements of its fellow rocks. It is not enough, though, that a group consist of decisionmakers to engage in cooperation. There is yet more in cooperation than the actions resulting from multiple but separate individual volitions that are each blind to the other volitions. ${ }^{22}$ Coordination of decisionmaking implies members of the group take account of the thinking of some others in the group.

I will use the term public to mean a group of cooperating individuals. ${ }^{23}$ How does a public coordinate its decisionmaking and thus cooperate? Law.

${ }^{21}$ Biologists have identified true communicative cooperation in non-human animals. "Recent theory and experimental studies suggest that hidden threats may play a similarly important role [as they do in human legal systems] in shaping the social behaviour of animals. In particular, threats to terminate a potentially profitable interaction may limit the level of selfishness in cooperative groups." M.A. Cant, The Role of Threats in Animal Cooperation, 278 PROCEEDINGS of THE RoyAl SOCIETY B: BiologiCAL SCIENCES 170, 170 (2010). Researchers have posited several requirements for hidden threats (potential sanctions) to be effective in fostering rule compliance among other animals. Most interesting, for this project, is the requirement that both those able to deliver on a threat and other members of the cooperating community have information concerning the nature of the threat and the values to community members of exit. $I d$. at 174-75 Thus, they must be able to run models of the sort I describe in Part III(C). It is unclear, though, whether some of our closest animal relatives infer and judge the models of other participants in the way I suppose humans do. See, e.g., Michael Thomasello, The UltraSocial Animal, 44 EURO. J. OF SOC. PSYCH., 187 (2014) (noting that "although many primates make simple causal and intentional inferences about external events, only humans make socially recursive and self-reflective inferences about others' or their own intentional states (e.g., she thinks that I think ....)").

${ }^{22}$ It is conceptually possible but hard to imagine non-intentional groups, where humans come together to accomplish a task that would be impossible without their joint inputs but where they are each unaware of the other. See UPSTREAM COLOR (film) (Shane Carruth, dir., 2013); see also CHRISTIAN List and Philip Pettit, Group Agency: The Possibility, Design, and Status of Corporate AGENTS 33 (2011) (noting the possibility of cooperation through cell-structures, where a coordinator brings together functional groups that are unaware of each other). My notion of cooperation does not require awareness of cooperation between each pair of participants, thus capturing cell-structured groups, but it does require participation in a decisionmaking group.

${ }^{23}$ This definition of a public demands more than some such definitions and less than others. Sociologists, in search of what we mean by "public opinion," have distinguished crowds, "defined by their shared emotional experiences," and masses, "defined by their interpersonal isolation." CARROLL J. Glynn, Susan Herbst, Mark Lindeman, Garrett J. O'Keefe, and Robert Y. Shapiro, Public Opinion 12 (3rd ed. 2016) (citing Vincent Price, Public Opinion (1992)). But a public is a group that discusses its divisions on issues confronting it. Id. at 13 (citing Herbert Blumer, Collective Behavior (1946)). Robert Park's notion of the difference between a public and a crowd strikes even closer to the idea here and to what follows: A public thinks and reasons together based on "facts," which are "idealized structures" that "take the place of concrete reality." They are idealized objects that make public communication practicable. ROBERT E. PARK, THE CROWD AND THE PUBLIC AND OTHER ESSAYS (1972).

Legal scholars have sometimes converged on the same notion. See Robert Post, The Constitutional Concept of Public Discourse: Outrageous Opinion, Democratic Deliberation, and Hustler Magazine v. Falwell, 103 HARV. L. REV. 633-38 (1990) ("A public, in other words, is constituted precisely by the ability of persons to speak to one another across the boundaries of divergent cultures."). Post's notion of a public was aimed at understanding the structure of public discourse and the role of the First Amendment in protecting that discourse. He drew on the work of sociologists who attempted to explain 
That is the word I will use to describe the conditions the group places on its members to achieve cooperation. ${ }^{24} \mathrm{Law}$, then, is an inevitable feature of cooperation. These basic definitions binding law and cooperation, which I call the Identity Framework, are fundamental. The framework does not, on its own, tell us much about law's nature or how to identify its content in a given instance of cooperation. But it delimits that which we hope to understand.

We can make several observations about law, so understood, based on uncontroversial assumptions about human beings. First, law must occur through communication: written laws, opinions, verbal orders, rules, the display of a firearm, and perhaps the information implicit in acts of enforcement. Indeed, any sort of coordination among human beings must somehow involve the transmission of thought through the air gap that separates our skulls. "There is no direct communion between the minds of men," but instead we must "resort[] to the outward manifestation of that which moves us inwardly, that is, to signs." 25 To engage in the practice of law, therefore, entails the processing and ordering of certain communications.

Second, and without loss of generality, we can describe these communications as effecting the public's management of its coercive resources. ${ }^{26}$ Such resources are present wherever there is cooperation, because, at the very least, discontinuing cooperation is always possible, as are other potential forms of inducement, from the potential to be recognized as a rule-breaker to explicit threats of violence. ${ }^{27}$ But no matter how plain or hidden, a public

how publics arise from mere groups in response to the challenge to cooperation posed by cultural diversity. Id. (citing Carroll Clark, The Concept of the Public, 13 Sw. Soc. SCI. Q. 311, 314 (1933)). But the apparent demandingness of the criteria for public-constituting discourse (of the kind the First Amendment is intended to protect) is not really any greater than my apparent undemandingness. Post required there be (1) more than a single culture so that there was some contest to be worked out through discourse, (2) a desire to preserve heterogeneity, (3) some common basis of communicative objects (facts, ideas, issues), (4) reasons to engage in the discourse (whether profit or other purposes), and (5) "commonly accepted standards of meaning and evaluation." Id. at 634-36.

It is interesting that these definitions share the concept of a group of communicating entities that have some common purpose, that are an interaction of minds and not just bodies. I require nothing more than that but also nothing less. Anything more embeds views concerning how cooperation is not just accomplished at all, but also how it is best accomplished.

${ }^{24}$ I define law here to describe a phenomenon invariably attached to cooperation, in other words law as cooperation's conceptual side. Later, in Part III, I will argue that its content arises from mutual acts of mental modeling by its participants. So the mere fact that law exists among a group can be verified by observing cooperation, but identifying law's content requires cognitive investigation.

${ }^{25}$ Francis Lieber, Legal and Political Hermeneutics, OR, Principles of InTERPRetation AND Construction in Law And Politics with Remarks on Precedents And Authorities 2 (1839). ${ }^{26}$ Turner supra note 20, at 121.

${ }^{27}$ My account of legal systems as bound to cooperation and as a sum of individual attitudes might seem to be "singularist" as Margaret Gilbert uses the phrase. See MARgaret Gilbert, On Social Facts 12 (1989). For Gilbert, understanding sociality as "'me watching you watching me' does not approach the heart of the matter." Margaret Gilbert, Joint Commitment: How We MAKe the Social World 4 (2014). Rather, joint commitment requires individuals each to commit to something in a way they all 
ultimately coordinates its decisionmaking through the management of these resources. ${ }^{28}$

While some scholars have rejected a focus on sanction as a defining characteristic of legal systems, ${ }^{29}$ they broadly agree on the centrality to law's functioning of coercive potential. As Robert Cover put it: "Legal interpretation is (1) a practical activity, (2) designed to generate credible threats and actual deeds of violence, (3) in an effective way." ${ }^{30}$ Even H.L.A. Hart, writing against the coercion-driven command theory of John Austin, ${ }^{31}$ recognized that "[1] egal rights and duties are the point at which the law with its coercive resources respectively protects individual freedom and restricts it or confers on individuals or denies to them the power to avail themselves of the law's coercive machinery." 32 We can relax any intuition we might have about coercion's martial nature and see it even in the mere withholding of approval or common recognition of defection. We can also take the view that a legal system uses coercion only as a means but that the purpose is to guide right conduct. What is inseparable from cooperation, however, is that there is transpersonal understanding of expectation and consequence, however vaguely appreciated.

Third, law, defined as broadly as I have here, is everywhere. Our world consists of many separate but interacting publics, and therefore legal systems. I am governed by the laws of the United States and the state in which I reside, local zoning ordinances, the terms of my employment, the constraints imposed by family, the norms of neighborliness, the terms of various contractual

understand commits them together and to one another. $I d$. at 7. It is this process that causes them to owe each other obligations, relations that cannot arise singularly.

I need not, in this introductory work, throw my lot in with John Searle, Michael Bratman, or Gilbert. I can build a legal theory by taking the fact of cooperation as both primitive and human-observable and assuming that people can recognize it, decide to enter it, and choose to be bound by corresponding obligations. That said, my theory does suggest a view of cooperation. But elaborating that view in a manner that engages the relevant philosophical literature on joint action is beyond the scope of this work.

${ }^{28}$ Christian List's and Philip Pettit's definition of joint intention captures much of the idea of a public and its cooperation that I identify here. See LIST AND PETTIT, supra note 22, at 33-34. It has four features: (1) a shared goal, (2) individual contribution, (3) interdependence (meaning that intentions are formed at least partly because of beliefs that others have the same intentions), and (4) common awareness (a belief that others have these beliefs about the group). They contrast a group of people cooperating to carry a piano downstairs, in which there is joint intention, to bargain hunters who collectively drive the price of a good down to a competitive level (a group that lacks joint intention among them). $I d$.

${ }^{29}$ SHAPIRO, supra note 15, at 77 (criticizing sanction-centered theories, namely Austin's, for failing to account for the people's common sense of obligation and not just threat arising from law).

${ }^{30}$ Robert M. Cover, Violence and the Word, 95 YALE L.J. 1601, 1610 (1986).

${ }^{31}$ John Austin, Lectures on Jurisprudence or the Philosophy Of Positive Law 88-106 (3rd ed.,1869) (characterizing law as the commands of a sovereign, habitually obeyed, backed by threats).

${ }^{32}$ HART, supra note 8, at 269. 
agreements, the morality into which I have become socialized, and other limitations of which I am hardly aware. We are the subjects of a cacophony of authorities arising from our membership in a corresponding cacophony of publics. Much of the trouble in legal theory-distinguishing "law" from mere "norms," for example-begins to resolve once we appreciate that a particular legal rule, norm, or moral principle is bound to one of the many different publics to which we belong. ${ }^{33}$

As will become more important in what follows, we can observe that how these publics are related, whether one is a subsidiary of another or otherwise related, is a matter of our point of view and the point of our comparing them. Contracting parties, for example, may not be a separate public but a private arrangement within a broader public. They are private parties using the apparatus of a state's laws to achieve their own purposes. This is neither true nor false. Rather it is only a possible description, or model, of complex phenomena occurring in the world.

A subgroup together with its purposes can be private relative to a public in two senses. First, it might be private in the sense that it is free to pursue its own conception of the good and that the public will use its coercive resources to aid in that effort. In this case, a coercive resource of this private group is the potential to resort to the coercive resources of the public in which it is embedded. For example, contract law is the body of law that identifies such private institutions and the conditions under which the public will lend its coercive resources to such institutions' privately made laws. When it does so, facilitating these private purposes becomes an objective, if not the only objective, of the public's cooperation. ${ }^{34}$

The other relevant sense of "private" is one implying a yet further degree of separation from the public of which the group's members are also a part. A private group within a public might pursue its purposes outside the system of conditional coercion maintained by the public. The maintenance of manners among friends, for example, might not be enforceable according to the rules of the state, a public of which they are also members. From the perspective of the state, whatever "law of manners" exists among these friends is "private private" law, not private law in the sense of the first type of private subgroup, as exemplified by contracting parties. Any enforcement of the

\footnotetext{
${ }^{33}$ See Part II(B), infra.

${ }^{34}$ See Gregory Klass, Three Pictures of Contract Law: Duty, Power, and Compound Rule, 83 N.Y.U. L. REV. 1726, 1769-73 (2008) (assessing that the existing body of contract law possesses both dutyimposing elements and power-conferring elements, the latter of which are concerned with advancing private purposes).
} 
friends' rules of manners must be accomplished through the coercive resources this group of friends maintains on its own, not those maintained by the public. ${ }^{35}$

Importantly, though, each private group, of either of the above two types, is yet another public when viewed from within itself by its members. A private group maintains its own coercive resources and has, as we will see in what follows, models for their use. This yields a principle of public relativity: that a group within a public can be viewed as a subgroup but also as constituting another public. A family is both its own public and a private entity within a broader public. A legislature is both its own public, its members bound by its rules, and a subgroup within the broader public that is the state. The way we perceive legal entities is a matter of perspective. The usefulness of a perspective depends on our reason for observing.

I will soon argue that individuals' dynamically generated mental models of cooperation are what give form and meaning to law, ${ }^{36}$ the conceptual side of the cooperation within a given public. Such models also give rise to whatever self-conception as a group its members maintain, that is to whether its members think of the group as an independent source of rules and obligations, an organ of the broader public, or both. But more on subgroups will follow after we have developed a concrete language of cooperation.

Finally, let us define an institution to be a subgroup of a public that communicates information that (a) the public takes into account when managing its coercive resources and (b) the subgroup's members intend to be so taken. ${ }^{37}$ Because legal systems are coordination by communication and because communication occurs between and among groups of people, we can model a legal system as a union of institutions and information.

As Robert Cover teaches:

The context of a judicial utterance is institutional behavior in which others, occupying preexisting roles, can be expected to act, to implement, or otherwise to respond in a specified way to the

\footnotetext{
35 The public has many choices to make concerning when to allow "private private" rules to be maintained and when to preempt them, prohibit them, or incorporate them. See, e.g., David Fagundes, Talk Derby to Me, 90 TEX. L. REV. 1093, 1131-1143 (2012) (arguing that the formalized but non-legal protection of roller-derby names is preferred by the derby community and enhances the community's values).

${ }^{36}$ See Part III, infra.

${ }^{37}$ We have not arrived at a theory of rules yet. Modeling theory and a theory of rules go together and will be developed below. See Part IV, infra. For now, the intuitive notion that a legal institution is one that generates legally relevant information will suffice. But I ultimately mean something broader by legally relevant than Hart's notion that a rule is given authority by a secondary rule which itself is ultimately dependent on a singular rule of recognition. HART, supra note 8, at 91-99.
} 
judge's interpretation. Thus, the institutional context ties the language act of practical understanding to the physical acts of others in a predictable, though not logically necessary, way. ${ }^{38}$

In the most important tract in the canon of legal positivism, H. L. A. Hart defined law as the union of primary and secondary rules, all ultimately backed by social acceptance of an ultimate rule that identifies the others. ${ }^{39}$ Hart's account is consistent with the picture of law I am developing. But I seek to extend his basic mechanism-acceptance of the rule of recognition- ${ }^{40}$ beyond a static frame in which participants either do or do not accept a singular, although potentially complex, ultimate rule. ${ }^{41}$ Ours is a world in which people are members of many, sometimes conflicting legal communities and in which different institutions within a community may radically differ concerning the cooperation. If we observe a group and are asking whether there is law among them, whether they are coordinating their decisionmaking, then as Hart correctly observed, ${ }^{42}$ we are asking something about their mental attitudes toward information they have produced. To explore that question but in the realistic context of dynamic and pluralistic societies, I will first develop some ideas about such attitudes and then turn to criteria for those attitudes to establish law. ${ }^{43}$

To summarize: A public is an instance of human cooperation. Every public can be identified with a legal system if law is defined as the conceptual side of that cooperation, the coordination of the public's decisionmaking. It comprises communications among the public concerning the management of the public's coercive resources. These communications occur among members of the public and between groups within it. Groups within a public can be viewed as a distinct public, as they form another cooperative instance, but also as subgroups of the public in which they are embedded. Families, legislatures, corporations, and groups of friends are both subgroups of a larger public and cooperating groups in their own right. Institutions are subgroups that supply legally relevant information, and thus we can describe a legal system as a union of institutions and information.

\footnotetext{
${ }^{38}$ Cover, supra note 30, at 1611.

${ }^{39}$ HART, supra note 8, at 97-99.

${ }^{40} \mathrm{Id}$. at $100-17$.

${ }^{41} \mathrm{Id}$. at 100 ("Wherever [the] rule of recognition is accepted, both private persons and officials are provided with authoritative criteria for identifying primary rules of obligation.")

${ }^{42} \mathrm{Id}$. at 88-91 (discussing "the internal point of view" of rules).

${ }^{43}$ See Part III(D), infra.
} 


\section{B. Law and Norms}

A description of a legal system sets out the conceptual side of an instance of cooperation in terms of discrete institutions and the informational connections between them. This suggests that there is law where we might intuitively only suspect there are norms. Indeed, the information-and-institution description of law reframes the burning question that has launched many a jurisprudential expedition: what properties distinguish laws from norms that are not law?

My answer is that there is no metaphysical difference between norms and laws as such. If an observer perceives one thing as a law and another as merely a norm, the real difference will ultimately be found in the distinction he or she makes between the cooperative communities that are their sources. One community contains the thing intuitively identified as a law and the other the thing identified as a norm. They are both publics, both with legal systems. Our intuition may want to find some essential difference in the information itself, in relations among bits of information, or in some endogenous property of relative bindingness distinguishing the law from the norm. ${ }^{44}$ But we look in the wrong place. Without distinct concepts of the communities associated with the information perceived as constituting the norm and with that perceived as constituting the law, there could be no way to distinguish the two in any language concerning authority or obligation. Obligation itself, including the necessity of strict compliance and the acceptability of deviation, derives from one's understanding of what a public requires. ${ }^{45}$

Not only is our attitude toward using the labels "law" and "norm" in fact dependent on our attitude toward the public whose conditions we are examining, but so too is our attitude toward true compliance or defection. Every

\footnotetext{
${ }^{44}$ Scott Shapiro distinguishes legal communities from other rule-bound planning communities using a property he calls "self-certifying." SHAPIRO, supra note 15, at 221. An organization is "“self-certifying' whenever it is free to enforce its rules without first demonstrating to a superior (if one exists) that its rules are valid." Being "free to enforce" means that the organization is not subject to higher authority or, if it is, "enjoys a general presumption of validity" from them. Id. Shapiro acknowledges that organizations lie along a spectrum of self-certfyingness, with the United States at one end, states close by, and condominium boards closer to lacking the property entirely. Id. at 222-23.

I think Shapiro is correct that bilateral hierarchical responsiveness is indeed an interesting property that can be measured at an instant in time. The degree to which one group must demonstrate to another group the validity of its rules before enforcing them might interest us. I do not think, however, that we gain much by drawing a stark line, as using the word "law" does, between the various communities that coordinate their decisionmaking. Nearly everything about the structure of rules, psychological attitudes toward them, and their fit with other systems applies just as well to municipal legal systems as to corporate governance, family structures, and the mafia. Indeed, some "official" legal systems may resemble the latter types more than they do our experience with the former.

${ }^{45}$ I discuss the problem of law's normativity within the modeling theory in greater detail in Part V(B).
} 
public yields a distinct domain of normativity. ${ }^{46}$ Each generates an obligating force like gravitation, posing to each participant the question whether and to what extent to join in its cooperative enterprise. Just as "mass" is the name we have to describe whatever it is that gives rise to an object's force of gravitation, so too "normativity" is the word we use to describe the obligating force. To violate a public's rule is to defect from its enterprise. And the morality of such defection is ultimately judged by the basic moral question of whether and to what extent cooperation within that public is good or bad. Thus law's normativity arises from the attitudes of participants toward the community's cooperation.

We have seen that publics and their corresponding legal systems can be identified with instances of cooperation and that legal systems work through institutions sharing information that is ultimately used to determine the application of coercive resources. Any group of people probably gives rise to many interacting publics. The normativity of each such public's law arises from the perceived morality of defection from the cooperation that defines the public in the first place.

But prior to any exercise of normative design, critique, or comparison, we should better understand these institutions, the information among them, how they are identified by participants, and what their relation is to what those participants would call the law. Are they defined specifically by law itself? Wouldn't that be circular?

If we take a public, its institutions, its information transmissions, and its informational networks among institutions as fundamental objects, then, yes, we have the basis for a model of the public's law. We have the vinegar and clay to make our model volcano, and we have the time, extent, and variables to simulate hydraulic flow in an idealized aquifer. But that is not yet an argument that such a description of law implies anything concerning the nature of

\footnotetext{
${ }^{46}$ It would appear that this claim puts me in direct opposition to Scott Hershovitz, who suggests we should be skeptical that there is a "distinctively legal domain of normativity." Hershovitz, supra note 9 , at 1186-92. But the very generality of my identification of publics and legal systems, and the suggestion that they are one, is actually a ground for believing his assertion that there is nothing particularly special, as a class, about traditionally recognized legal systems. Thus, I ultimately agree with Hershovitz that a legal system does not create a distinctively "legal" set of reasons for complying with its commands. But that is because I think obligation-generation is a property of a public, a property of each group to which one belongs. They are all distinct domains of normativity. But our reflective attitude toward traditionally labeled legal regimes is not different in kind than our attitude toward compliance with other regimes, other publics to which we belong. As to all, the morality of defection from the conditions of cooperation follow from moral judgments concerning the cooperation itself. And so "we can represent law as continuous with the other normative practices." Id. at 1193.
} 
legal disagreement or, more broadly, what might control the origins, mutations, and deaths of patterns of legal practice. What else can we say about models of this sort?

\section{THE MOdELING THESIS}

\section{A. Why Models?}

I have argued thus far that law is the conceptual side of cooperation and that it can be modeled as a network of institutions and information among participants. I now wish to go further and to argue that not only can a legal system be modeled but that it can also be understood as an emergent property of acts of modeling by the participants in a cooperative enterprise.

In Legality, Scott Shapiro begins by discussing, just as Hart did, what a funny question it is: "What is law?" observe. Medical professionals just sort of get on with it and do not seem to be hampered by asking themselves what they are doing when they set a bone or resect a tumor. As a student of jurisprudence, I had taken as true this starting point for elaborating the concept of law, that our job was to understand law's distinction from these other fields. But I am now convinced that doing so is the beginning of an error. Distinguishing law from disciplines that seem unconcerned with their concepts puts us on a trajectory to define law's specialness. But law is not special. In fact, our thoughts about law are not unlike our thinking about other aspects of our experience.

After all, people do indeed ask "what is medicine" and "what is the body." We in fact provide different answers in different situations to the question of what the human body is, and we unthinkingly shift between them. What medicine is and what a surgeon does, those things are functions of the particular way of thinking of the body that seems most responsive to whatever the problem at hand is. And so while we may not ask out loud what the human body is, we do answer that question implicitly and repeatedly.

Whatever its smallest parts, the body has a separate identity as a concept only because of our higher level descriptions of the patterns of matter that compose it and the consequences its existence can create. Depending on the question being asked, the human body can be described as its whole form animated by human behaviors over time, as a combination of major organs and their arrangement in a given instant, as an organization of tissues, as a pattern of molecules, as characteristic patterns of atoms and energy, as

\footnotetext{
${ }^{47}$ SCOTt J. Shapiro, Legality 1 (2011); HART, supra note 8 at 1.
} 
quarks. The term "body" is itself a conceptual object, hiding behind a single word immense complexity and containing within it ever more detailed conceptual objects that need only be consulted if the question of the moment goes that deeply.

So too everything! The world, to us, is not a thing, but our mental representations concerning idealized versions of things and abstract relations among things. A cathedral exists as a "cathedral" only in our minds. What we label "cathedral" is a particular set of ideas and stories about our relation to certain arrangements and evolutions of matter, not the arrangements themselves. We function by maintaining not just abstract tokens representing perceptions of things but mental models of our world.

In 1943, the psychologist Kenneth Craik advanced this idea in The Nature of Explanation:

By a model we thus mean any physical or chemical system which has a similar relation-structure to that of the process it imitates. ... . My hypothesis then is that thought models, or parallels, reality - that its essential feature is not 'the mind,' 'the self', 'sense-data', nor propositions but symbolism . . . . If the organism carries a 'small-scale model' of external reality and of its own possible actions within its head, it is able to try out various alternatives, conclude which is the best of them, ... and in every way to react [better] to the emergencies which face it. ${ }^{48}$

Craik "suggested that the mind builds small-scale models of the world, which it uses to anticipate events and to guide its decisions. Mental models are constructed as a result of perceiving the world, understanding descriptions, and imagining possibilities." 49

Researchers Stefan Groesser and Martin Schaffernicht describe mental models as comprising logical assertions that are linked and then used with input data to reach conclusions. ${ }^{50}$ They ultimately suggest a more complex understanding of mental models of dynamic systems, but, for now, the important point is that an internal representation of a system is "run" in the mind to make decisions and to understand complexity.

A mental model is constructed in working memory and can then be run like a computer simulation allowing an individual to ex-

\footnotetext{
${ }^{48}$ Kenneth Craik, The Nature of Experience 53 (1943).

${ }^{49}$ P. N. Johnson-Laird, Causation, Mental Models, and the Law, 65 BrooK L Rev 67, 70 (1999).

${ }^{50}$ Stefan N. Groesser \& Martin Schaffernicht, Mental Models of Dynamic Systems: Taking Stock and Looking Ahead, 28 Syst. Dyn. REV. 46, 48 (2012).
} 
plore and test different possibilities mentally before acting. Working memory is the system responsible for selecting and manipulating information for the purpose of reasoning and learning. Changes made to a mental model in the simulation process represent what would happen if such changes took place in reality. ${ }^{51}$

In fact, cognitive scientists have suggested that the human conceptual system is a simulating system. Our thinking, under this view, is "a distributed neural mechanism that constructs an infinite set of specific simulations to represent a category, property, or relation dynamically. Thus, the simulator for chair can construct many simulations of different chairs, from different perspectives, used for different purposes, reflecting the agent's current goal and situation." ${ }^{, 52}$ Running the model on hypothetical data in fact simulates experience, engaging versions of our actual sensory experiences and triggering affective reactions. ${ }^{53}$

Of course, the models we maintain are flawed, may be inconsistent with one another, and exist at many scales:

Peoples' ability to represent the world accurately, however, is always limited and unique to each individual. Mental models are therefore characterized as incomplete representations of reality. They are also regarded as inconsistent representations because they are context-dependant and may change according to the situation in which they are used. In essence, mental models have to be highly dynamical models to adapt to continually changing circumstances and to evolve over time through learning. Conceptualizing cognitive representations as dynamic, inaccurate models of complex systems acknowledges the limitations in peoples' ability to conceive such complex systems. ${ }^{54}$

\footnotetext{
${ }^{51}$ Natalie A. Jones et al., Mental Models: An Interdisciplinary Synthesis of Theory and Methods, 16 ECOL. AND SOC. 46 (2011).

${ }^{52}$ Lawrence W. Barsalou, The Human Conceptual System, in THE CAMBRIDGE HaNDBOOK OF Psycholinguistics 239-258 (Michael Spivey, Ken McRae, \& Marc Joanisse eds., 2012).

${ }^{53}$ See, e,g., Lawrence W. Barsalou, Situated Conceptualization: Theory and Applications, in 1 Foundations of EMBODIED COGNITION: PERCEPTUAL AND EMOTIONAL EMBODIMENT 3-6 (contrasting the "sandwich model," which finds cognition as a modular process existing in the brain between perception and action, with "grounded cognition," which views cognition as inseparable from sensory perceptions and physical action).

${ }^{54}$ Natalie A. Jones, Helen Ross, Timothy Lynam, Pascal Perez, and Anne Leitch, Mental Models: An Interdisciplinary Synthesis of Theory and Methods, 16 ECOLOGY AND Soc'Y 46, 46-47 (2011).
} 
Further, people think in terms of analogies, meaning that mental models are "analogous representations" and not just convenient translations of abstract thought processes for purposes of communicating. ${ }^{55}$

There is no reason to suspect that our understanding of law manifests and operates differently than does our understanding of anything else we experience. As Lynn Lopucki has written:

When law is applied, it is always through the agency of a human mind. That mind must absorb both the law and the situation to which it is to be applied, represent them internally, make the application, and report the results. It is mental representations-referred to in the cognitive psychology literature as "mental models"-not written law, by which lawyers and judges process cases. They can and sometimes do describe the law contained in their mental models in speech and in writing. The law in those models is remarkably simple, virtually black letter. That simplicity embarrasses the lawyers and judges. When pressed on a point, they are likely to scramble for a book or offer to prepare a memorandum. $^{56}$

When we say that one has an understanding of a group's law, we mean, necessarily, that he or she has a satisfactory mental model of its practice. To talk about a complex social practice is, if one looks closely enough, to describe the scarcely even countable number of interactions of many trillions of atoms. ${ }^{57} \mathrm{~A}$ model, in the sense of mathematics or the natural sciences, is a toy universe, a game with a small number of pieces and rules, the playing of which may analogize well or poorly to the features of reality in which one is

\footnotetext{
${ }^{55}$ Id. Sociologists have long observed that interaction, cooperation, and description are only possible on account of abstraction. See, e.g., Floyd N. House, Social Relations and Social Interaction, 31 Am. J. Soc. 617, 630 (1926) ("We are able to deal with this concrete reality, however, in a more or less sophisticated and purposive way, by categorizing it, that is by subjecting it to a procedure of conscious or unconscious abstraction. [T] he most natural kind of abstractions which we make from the reality of experience are probably those in which we reduce the reality to a substantive form . ..."). Cf. MAX Weber, On the Methodology of the Social Sciences 89-94 (1949) ("In its conceptual purity, [the ideal type] cannot be found empirically anywhere in reality. It is a Utopia. Historical research faces the task of determining in each individual case, the extent to which this ideal-construct approximates to or diverges from reality. ... . [Ideal types] appear in full conceptual integrity either not at all or only in individual instances. Here as elsewhere every concept which is not purely classificatory diverges from reality. But the discursive nature of our knowledge, i.e., the fact that we comprehend reality only through a chain of intellectual modifications postulates such a conceptual short-hand.").

${ }^{56}$ Lynn M. LoPucki, Legal Culture, Legal Strategy, and the Law in Lawyers' Heads, 90 Nw. U.L. REV. 1498, 1500 (1996).

${ }^{57}$ Even to narrate reality as the evolution of positions and energies of atoms is to speak within the bounds of a particular model. Atoms, themselves, are high-level constructs.
} 
truly interested. ${ }^{58} \mathrm{~A}$ metal rod across which heat is conducted may be described as a one-dimensional continuum, each point possessing a finite number of qualities, like heat energy and density. A group of ranchers on an open rangeland may be described as calculating machines with maximization goals, the rangeland basically a resource equivalent to a number, the ranchers' actions being still other numbers with fixed relationships to the rangeland's numbers. ${ }^{59}$ A volcano is modeled with clay, baking soda, and vinegar. The science fair participant's attitude toward this tabletop construction is driven by the small number of features of the actual volcano he or she believes salient in producing the phenomena associated with it that are of interest at the time.

It might only be a difference in rhetorical emphasis, but I focus on the language of models and their objects instead of the language of concepts. It is not so much that the notion of concept is too cramped, but, rather, the opposite: Its very generality pushes us perhaps to worry too much about legal participants' failure to share a single concept of law. The language of modeling is more constrained, more suggestive of the adaptability of a mindset to the particular problem in front of it. In the modeling theory of legal systems, there is simply the perceived fact of cooperation, and the human perceivers build models of that cooperation, both as they perceive it and as they wish it to be. They judge the cooperation based on these models, and they negotiate and argue for modifications, rejections, and acceptance of models. Modeling, unlike inquiring into a concept, is obviously to perceive, to simplify, and to approximate. $^{60}$

Viewing law as the cooperation of modeling agents also seems to fit what we observe about legal argumentation. It accounts-as may already be

\footnotetext{
${ }^{58}$ See, e.g., R.I.G. Hughes, Models and Representation, Proceedings of the 1996 Biennial Meeting of the Philosophy of Science Association, 2, S325-S336 (2008). Hughes nicely describes the process and use of the modeling of physical reality as a composition of denotation, demonstration, and interpretation. Id. at S328-29. "A mathematical representation should not be thought of simply as an idealization or an abstraction. Like an analogical representation, it presents us with a secondary subject that has, so to speak, a life of its own. In other words, the representation has an internal dynamic whose effects we can examine. From the behavior of the model we can draw hypothetical conclusions about the world over and above the data we started with." Id. at S331.

It is no accident that so many philosophers of law have been drawn to the rules of games as analogies. See, e.g., HART, supra note 8 , at 142-145. The only mistake in so doing, as I will argue, is failing to recognize that the playing of games is more than just analogous to conducting a legal regime, it $i$ conducting a legal regime.

${ }^{59}$ See Garrett Hardin, The Tragedy of the Commons, 162 SCIENCE 1243, 1244-45 (1968).

${ }^{60}$ This thesis concerning our subjective experience of law is consistent with emerging theories of the human conceptual system. "Rather than being a single abstracted representation for a category, a concept is a skill for constructing idiosyncratic representations tailored to the current needs of situated action. . . . . Barsalou proposes the construct of a simulator as a distributed neural mechanism that constructs an infinite set of specific simulations to represent a category . . . dynamically." Lawrence W Barsalou, The Human Conceptual System, in THE CAMBridge HANDBOoK OF Psycholinguistics 239, 251 (Michael Spivey, Ken McRae, \& Marc Joanisse eds., 2012).
} 
obvious but as we will see below-for basic, theoretical disagreement and yet is grounded in empirical fact.

\section{B. Mental Models and Object-Orientation}

Whatever the fundamental, ontological status of, say, a cathedral and whatever one might believe to be the nature of the physical reality of the universe, when it comes to our cooperation with respect to the cathedral, it certainly must be understood as consisting of our thoughts about it. We talk to one another concerning the models we maintain about the cathedral, models that must ignore and obscure the irrelevant and highlight the salient, where irrelevance and salience depend on the point of our cooperation at the moment. When we talk of doorways, pews, and altars rather than stone, wood, and metal, it is because we are able to cooperate by coordinating our models to solve the problems in front of us.

The more complex the system, the more obvious is our inevitable resort to what computer programmers call "object-oriented design." ${ }^{, 61}$ One example that leads to particularly quick understanding of the power of this modeling language is the simple clock. ${ }^{62}$

A clock hides behind a simple face much complicated machinery. As an object, it exposes to the user an interface of very simple informational components. You can "ask" the watch what time it is and read the response by looking at the hands. To answer your question, the watch must engage in complex processing, but it hides all of that from the user. If someone invented a better way to produce answers to the "what time is it" question (a better internal mechanism), the internals could be replaced, but the user interface could remain exactly the same.

To solve practical problems in ways human beings can understand, series of complex events and long lists of granular instructions can be replaced by a relatively small network of message-passing objects, each object responsive to a small number of discrete queries. The immensity of the time-keeping problem can be hidden, conveying to the watch-wearer the singular piece of information that may interest her: the time.

\footnotetext{
${ }^{61}$ See, e.g., William Li, Pablo Azar, David Larochelle, Phil Hill, and Andrew W. Lo, Law Is Code: A Software Engineering Approach to Analyzing the United States Code, 10 J. BuS. \& TECH. L. 297, $313-$ 14 (2015) (describing object-oriented software design).

${ }^{62}$ My initial education on object-oriented design was a much older version of these documents, Apple's explanation of object-oriented programming and Objective C: https://developer.apple.com/library/ ios/documentation/Cocoa/Conceptual/OOP_ObjC/Introduction/Introduction.html\#//apple_ref/doc/uid /TP40005149-CH1-SW2. I have borrowed the clock example from the explanation contained in these documents' predecessor.
} 
Within the watch, we can find springs and gears and mechanisms, even as we could look yet more closely and describe more and more detailed material components. Perhaps the makers of one component have no idea how to manufacture another or even how the other components work. All that is necessary, though, for their participation in the cooperative enterprise of watch manufacture is to know the discrete details concerning how the parts relevant to their component will function when acted upon - acted upon in one of the discrete ways that each part is designed to act. Your mechanism, for example, must respond to the constant turning of a motor, and it must translate that energy into a heartbeat turning of a gear. How does it do that? The wearer need not know. The maker of the battery need not know. The maker of the glass that protects the face need not know. Nor do you need to know anything about their workings or purposes other than their interface with your component.

The important principle is this: We can make a watch together if we master the potentially complex construction and details of our own parts and design them to communicate simply with the parts made by others. And this we can do if we share a simple model of communicating parts.

Conceiving of a system as composed of simple, communicating objects makes intensely intricate tasks possible by hiding substantial amounts of complexity. As Henry Smith and Thomas Merrill have observed in the context of property law, bundling complexity inside discrete objects that expose only simple interfaces saves what would be high costs of interaction were our descriptions of things always in terms of basic components. "Property" and "ownership" are such objects, hiding a great many details concerning how such statuses might be recognized and lost. The law endeavors, to the extent compatible with other commitments, to "objectize" these terms, to sweep vast clusters of event descriptions under these labels, so that in many disputes we can ask the simple question whether there is "property" and then do the things we have determined to do when there is or when there is not. We do not need long lists of rules specifying what is to be done when someone takes another's car, house, food, furniture, paper, computer, etc. The notion of "theft" queries the "property" class of objects as a class, ${ }^{64}$ not a "diamond necklace" object in particular.

\footnotetext{
${ }^{63}$ See Thomas W. Merrill \& Henry E. Smith, Optimal Standardization in the Law of Property: The Numerus Clausus Principle, 110 Yale L.J. 1 (2000); see also Thomas W. Merrill, Property as Modularity, 125 Harv. L. Rev. 151 (2012); Henry E. Smith, Property as the Law of Things, 125 HARV. L. REV. 1691 (2012).

${ }^{64}$ In many object-oriented programming languages, classes of objects are themselves objects. See, e.g., Hal Fulton AND ANDrè ARKo, The Ruby Way 33 (3d ed. 2015).
} 


\section{Law as Object-Oriented Modeling}

In explaining what law's practice is, we are necessarily explicating a model of idealized parts and rules. Legislatures, attorneys, statutes, adjudication: no matter how detailed our description of these parts, our use of them in explaining the physical reality of law can only be by analogy. And indeed, by talking as if the pieces and rules of our hypothetical game are the real things themselves, we sometimes elide the possibility that one source of theoretical disagreement is the use of different models to describe what those in disagreement are observing, that the actual disagreement is about the right choice of models. ${ }^{65}$ A legal argument operates within a model, proceeding according to its rules and objects, and thus passes over acres of vacant intellectual terrain, the unargued, unremarked landscape of reality that the model idealizes. To put it concretely, our model tells us what needs to be argued with facts and theory and what can be assumed or otherwise ignored.

That the simplification of concerted activity is central to both law and computer science has not gone completely unnoticed by scholars, but neither has it been particularly central to legal theory. While some researchers, in various fields, have explored the connections between law and computer science, ${ }^{66}$ only a few have remarked on that connection as more fundamental

${ }^{65}$ Felix Cohen is famous for his devastating critique of judicial use of unreal constructs, like "corporation," as though they have physical substance, obscuring actual reasons for decisions with fake-physical nonsense. Felix Cohen, Transcendental Nonsense and the Functional Approach, 35 Colum. L. Rev. 809 (1935). But even Cohen noted that transcendental categories had their utility. "[M]yths may impress the imagination and memory where more exact discourse would leave minds cold." Id. at 812. Models, though, are more than myths. They are our reality, not lies we tell ourselves. The sin identified by Cohen was circularity, not the fact that all our categories never quite map the world as it is.

${ }^{66}$ There is a surprisingly sparse literature on the similarities between legal systems and complex software. One line of research, which seems to have been prominent when personal computing was new, is concerned with understanding law in a way that could be reduced to computation. See, e.g., Jon Bing, Legal Rules, Discretionary Norms, and Computer Programs, in COMPUTER SCIENCE AND LAW 119-22 (Bryan Niblett, ed.) (1980) (describing the steps of legal decisionmaking, from legal sources to interpretation to actionable legal norms, and noting the potential for reduction to interpretive compilers); Susan Jones, Control Structure in Legislation, in COMPUTER SCIENCE AND LAW 157-67 (Bryan Niblett, ed.) (1980) (attempting to replicate the procedure and substance of an intestate succession statute using the computer language LEGOL2, focusing on control flow structures); R Kowalski \& M Sergot, The Use of Logical Models in Legal Problem Solving, 3 RATIO JuRIS 201-218 (1990) (suggesting the modeling of law in ways that could be reduced to computation using logicoriented programming languages and identifying simple applications of law that lend themselves to calculation, including aiding in drafting by testing outputs and serving as expert systems for lawyers to test scenarios of legal application); Herbert Fiedler, Functional Relations Between Legal Regulations and Software, in COMPUTER SCIENCE AND LAW 144 (Bryan Niblett, ed.) (1980) ("It can be hoped that legal theory in general is able to realize that there are important requirements for the law analogous to the objectives of programming methodology in its more modern forms. Such requirements are, e.g., understandability, modifiability, eventually even something like demonstrability of correctness of legal regulations with regard to definable tasks."). 
than mere analogy. Thomas Blackwell, for one, has noted the power of object-oriented design in computer programming to facilitate the cooperative creation of highly complex applications and argued that such a design paradigm should be applied to legislative drafting. ${ }^{67}$ In the course of asking to what extent the practice of law is science, M.C. Roos notes the important roles of abstraction, systematization, and reflection that are key to the practice of both. ${ }^{68}$ What leads Roos to suggest law is a science is the development in law of an abstract system of objects and a theory that structurally relates objects to one another. ${ }^{69}$

The author closest to the fuller approach I advocate here is Garrett Wilson, who wrote a truly remarkable, unpublished paper as a law student exploring the deep connection between law and computer code. ${ }^{70}$

At a fundamental level, the evolution of the common law and the iterative improvement of computer software are based upon some of the same analytic philosophy concepts developed in the Twentieth Century relating to conceptions of reality, linguistics, and set theory. At their heart, both professions depend on model creation, model application, and model revising or refactoring .... While

There is, however, some more recent scholarship exploring the analogy, perhaps induced by a perceived second-wave of computation in social science, the era of big data. See generally W. Li et al., Law is Code: A Software Engineering Approach to Analyzing the United States Code, 10 J. Bus. \& TECH. L. 297 (2015).

${ }^{67}$ Thomas F. Blackwell, Finally Adding Method to Madness: Applying Principles of Object-Oriented Analysis and Design to Legislative Drafting, 3 N.Y.U.J. LegIS. \& PUB. PoL'Y 227, 268-87 (1999). Blackwell helpfully summarizes the object-oriented design pattern as, first, an analysis phase: "(1) identification of relevant concepts in the real world; (2) identification of attributes of those concepts; (3) identification of relationships between those concepts; and (4) reassembly of those concepts, attributes, and relationships into a conceptual model that accurately and unambiguously describes the problem domain. This conceptual model is then refined through successive iterations until it is complete." Id. at 274. This is followed by the design phase, "[t]he heart of [which] is the creation of interaction diagrams, which illustrate how objects will communicate in order to fulfill the requirements." Id.; see also Li et al., supra note 66, at 13-15 (noting that object-oriented methodologies in software achieve the goals of abstraction and modularity, goals that can and should be pursued in statutory analysis).

${ }^{68}$ M.C. Roos, Is Law Science? 17 Potch EleKt Regs 1392, 1417-27 (2015).

${ }^{69}$ Roos characterizes law as science by arguing for a conception of science that emphasizes behavioral elements, rejecting notions that it is defined by its domain of objectivity, that it is identical with the generation of falsifiable statements, that it is puzzle-solving, or that it is whatever produces useful knowledge. Id. at 1401-11. Rather science is the cognitive function of abstracting the world, systematizing it, and reflecting on the system. Id. at 1414. "Abstraction also leads to creative cognitive functioning and the ability to cope with more complex tasks or situations." Id. Roos goes on to explain the distinction between unscientific "entitary" abstraction (the breaking of perception into abstract parts, like the parts of a cow) and the scientific "modal" abstraction (the sort that is concerned with the structured relations among objects). Id. at 1417-18.

70 Garrett Wilson, Refactoring the Law: Reformulating Legal Ontologies (2006), at http://www.garretwilson.com/essays/law/refactoringlaw.html. 
the three year training course that is law school tries to help law students develop an intuitive understanding of how law "works" and evolves, the software profession is currently ahead of the legal profession in creating procedures and frameworks for identifying what makes conceptual models logically elegant; and when and how these models should be changed. ${ }^{71}$

Wilson nicely suggests a symmetry between the evolution of law and the evolution of software. On the one hand, we observe law's evolution from a more procedural orientation (the legal world of writs and forms of action that specified more particular law to resolve particularized disputes, walling off areas of law that were conceptually similar) to class-orientation (the increased mapping of legal concepts to real-world categories and the abolition of fictions). On the other, we find software's evolution from procedural code (programs as series of instructions) to object-oriented code (programs that, among other things, model reality and contain hierarchies of communicating, detailhiding objects). ${ }^{72}$

The uncertainties and controversies arising in our practice of law become a little more obvious when we realize that each understanding we have of a legal system is a distinct model consisting of communicating, idealized objects. What we know about a legal system at any given moment is a simplification and an abstraction in which millions upon millions of real and potential human interactions are shepherded into a much smaller number of rules and institutions. We have courts, legislatures, agencies, international bodies, families, sports leagues, statutes, regulations, and decisions. We have ideas like causation, defense, lawsuit, property, jurisdiction, statutes, and speech that, depending on the dispute, we often either observe as being present or absent, and then connect that fact directly to other objects and arguments. Sometimes, though, we "unpack" and argue about more basic components of these ideas. ${ }^{73}$ And from models that consist of these objects, we "do" the law. We force people into prison, force the payment of money and the delivery of services, and kick people out of clubs. We kill people. We stop government agents from spying or even require them to spy. We dissolve failed marriages and business partnerships.

At a very low level, but even here not so close to the metal that we can dispense with the label "model" and call it "reality," all of these activities are

\footnotetext{
${ }^{71} I d$.

${ }^{72} I d$.

${ }^{73}$ Compare, e.g., Cohen v. California, 403 U.S. 15, 18 (1971) (easily finding words of protest on a jacket to be "speech" within the meaning of the First Amendment), with United States v. O'Brien, 391 U.S. 367, 376-83 (1968) (distinguishing conduct from speech and focusing on the reasonableness of the government's regulation of the conduct of mutilating a draft card).
} 
atoms and energy, as with the human body and the clock. What is the practice of law? Like the body itself or the working of the clock, the practice of law is just patterns of energy and atoms. ${ }^{74}$ That is certainly true. Law might be described completely by physics and mathematics. It certainly could be described more precisely in those terms. We do not, however, send our law students across the quad to the physics and math departments and call it a day. Not only do we not have the power to model legal systems at the level of atoms, it seems the wrong level to conceive of our history of cooperation when trying to determine how that cooperation should proceed. ${ }^{75}$

Return for a moment to consider all of the vacant terrain we unthinkingly crossed in our earlier discussion of disputes and resolutions. What is a dispute? At a very broad level, it consists of certain features of the moments when the plans or desires of two humans conflict in such a way that those plans and desires cannot both be fully met and so cooperation is potentially obstructed. However satisfying or unsatisfying that description might seem, it positively bleeds imprecision. More precision, though, asks us to define our terms better. Ok, then, what is a human? Does this level of precision matter? Could it ever matter, in the sense that competing but reasonable understandings of the concept of a human could lead to different legal conclusions?

I will not continue down the road of elucidating the manifold concept of a human being. My purpose here is not to suggest that all descriptions of law that posit the existence of something called a human being are fatally flawed. I will take it as given, for example, that we can say without dispute in most cases what a human being is. I bring it up because it is useful, indeed critical, to ask why it is that I am almost always comfortable taking the concept of "human" and a host of other concepts for granted. And yet in a few cases, the apparently vacant terrain containing the more particular and competing conceptions of "human being" is revealed as vibrant and important. The concept of a human being is opened and disputes about its components are had. ${ }^{76}$

\footnotetext{
74 "Just" is an overly derisive term to describe the majesty of small-scale nature that produces these recognizable high-level social systems. "Is it possible that that 'thing' walking back and forth in front of you, talking to you, is a great glob of these atoms in a very complex arrangement, such that the sheer complexity of it staggers the imagination as to what it can do? When we say we are a pile of atoms, we do not mean we are merely a pile of atoms, because a pile of atoms which is not repeated from one to the other might well have the possibilities which you see before you in the mirror." RICHARD P. Feynman, Robert B. Leighton, Matthew SAnds, 1 The Feynman Lectures on Physics, I-9 (1963). ${ }^{75}$ See Jones et al., supra note 51. ("A mental model is a simplified representation of reality that allows people to interact with the world. Because of cognitive limitations, it is neither possible nor desirable to represent every detail that may be found in reality. Aspects that are represented are influenced by a person's goals and motives for constructing the mental model as well as their background knowledge or existing knowledge structures ....")

${ }^{76}$ See, e.g., Kirsten Rabe Smolensky, Defining Life from the Perspective of Death: An Introduction to the Forced Symmetry Approach, U. CHI. L. FORUM 41, 51-62 (2006) (discussing difficult cases raising the question of the meaning of "human being").
} 
If we inevitably traverse under-theorized terrain, perhaps legal understanding itself requires us to do so. When we take a concept like "human" for granted, declining to go further into its nature, we are using a model of the legal system that considers a human being to be a particular kind of physical entity that can receive informational inputs and produce behaviors, including informational outputs, in a restricted range (or that at least resembles such an entity in a way that leads us to treat it like one that can). While we might, in some cases, become interested in how exactly humans do that - how we decide what to do based on stimuli - and in how to value their choices and what we call their well-being, we will rarely if ever find it useful to construct a model of legal systems that conceives of humans at the molecular level but no higher. Humans are, from our legal perspective, objects hiding complexity, the hands on the watch face that we know hides complex springs and gears.

\section{Criteria for Law}

We are now ready to define the phenomenon that is a legal system. It will necessarily be in terms of individual models and perceptions of the models of others. To repeat: All our conceptions of law are abstract, object-oriented, mental models of a social practice. These models consist of informational networks of connected objects. The "true" nature of these objects and their communications is only modeled, and we hold in our heads an abstract, simplified set of rules and tokens that represents the objects' physical compositions and utterances. Indeed, any sufficiently complex process that we wish to understand and discuss must ultimately be reduced to a non-real, conceptual model of interacting objects. When a person calls a thing "law," she is engaging in just such a process.

Importantly, none of us maintains a single such model. Our working conception of the legal system depends on the reason we are thinking about it. Sometimes, for example, when deciding how to answer a legal question, we might ask whether a "legislature" "passed" a "statute." Whether we need to dwell on the nature of each of those terms depends on the question we are asking and the attitudes of the participants toward that question and those terms. Does it matter that the legislature is in fact an institution comprising individual people, people who also compose sub-institutions like committees and separate "chambers" of the legislature? ${ }^{77}$ Maybe, maybe not. Perhaps we agree on what these terms mean for this case, that we are satisfied looking

\footnotetext{
${ }^{77}$ For example, in most cases, our model of the legislative branch may consist only of an abstract entity we think of as "The Legislature." This model was insufficiently detailed for the debate in INS v. Chadha, 462 U.S. 919 (1983) (striking down a statute giving a single House of Congress the authority to veto certain executive actions).
} 
only at the hands of the watch, and so we talk about law through the interface exposed by this very simple model. Perhaps, though, one of us will not accept this model as to this question. Our disagreement might concern what it means to "pass" a statute, and we must turn to a more complicated model, one containing springs and gears (but still not molecules), that accounts for principles of majoritarianism. We are "doing law" when we can agree to accept another's use of a model to resolve such questions, even if the model leaves room for disagreement among us on the right outcome.

To develop criteria for law, we start with a single individual and measure his or her attitudes about an instance of cooperation. I claim that he or she maintains a model of the relevant portion of the legal system, one that connects questions about the conditions of cooperation with information concerning those questions. A more precise language for describing such models in terms of institutions and rules will be taken up below. For now, let us focus on what we mean by a legal system among a group of people who maintain such models, however described.

A locally preferred model is a model of the legal system (concerning anticipated input data) that an individual would prefer to use to answer a question.

A local actual model is a model of the legal system that an individual uses to govern his or her own actions within the legal system. It may or may not be his or her locally preferred model. ${ }^{78}$

A locally identified model is a model of the legal system (concerning anticipated input data) that the individual believes to be a local actual model of a cooperating participant. It is, of course, possible to make a mistake and to identify a model that another participant is not in fact using. E.g.: $Y$ locally identifies a model used by $X$ as: " $X$ makes decisions according to the rules he interprets in the King James Bible." But $X$ 's actual model is: "I $(X)$ make decisions that make me wealthier so long as they can be plausibly passed off as consistent with the King James Bible."

\footnotetext{
${ }^{78}$ I allow that the actual model can differ from the preferred model for two reasons. First, it is possible for a decisionmaker to be unprincipled: to prefer that model $A$ be used to answer questions of type under consideration but to use model $B$ for reasons she wishes not to see repeated. A common form of legal disagreement, though perhaps aggressive enough not often to be made explicit, is believing another participant had previously argued for model $A$ but that only model $B$ can explain her decision now. See, e.g., Zant v. Stephens, 462 U.S. 862, 910 (1983) (Marshall, J., concurring) ("Today we learn for the first time that the Court did not mean what it said in Gregg v. Georgia. We now learn that the actual decision whether a defendant lives or dies may still be left to the unfettered discretion of the jury.").

The other possibility is that the actor is making a subconscious, intuitive decision using one model but would articulate the application of another, reasoned model. Cf. Jonathan Haidt, The Emotional Dog and Its Rational Tail: A Social Intuitionist Approach to Moral Judgment, 108 Psych. ReV. 814, 817-19 (2001) (describing the "social intuitionist model" of moral judgment, in which quick intuitive moral decisions are followed by slow, post hoc reasoning).
} 
Local acceptance occurs when an individual accepts a locally identified model, in the sense that the individual prefers continued cooperation in the face of behavior by another consistent with the locally identified model.

Mutual acceptance occurs among participants when they each locally accept a locally identified model with respect to every other participant. Mutual acceptance does not require a single understanding of law. It does not require agreement concerning what outputs to produce but, rather, can manifest agreement to disagree. Nor does mutual acceptance even require a coherent external description of the members' agreements and disagreements concerning decisionmaking. For example, Participant One identifies model A as being used by Participant Two. Participant Two identifies model B as being used by Participant One. Model A and model B may be incompatible, in the sense that they lead to different decisions on many important questions, and, yet, it is possible that Participant One accepts Participant Two's use of A and vice versa. That is mutual acceptance but not mutual acceptance of a single model.

A model is to a shared model if every member maintains an identical local actual model. Almost inevitably, shared models exist, if at all, at a high level of abstraction. But there need not be a single, shared model at all. The cooperation may proceed by universal toleration or mistake rather than agreement. Whether the legal system is stable, in the sense that the cooperation is likely to continue, could depend on the paucity of such mistakes, especially if decisions that will reveal the mistakes arise.

Hart identifies a legal system with the fact that there exists some shared model among officials (the rule of recognition) and mutual acceptance of the more detailed models of a legal system within a group. ${ }^{79}$ This fact is social, not logical or moral, in nature, in that it describes a contingent condition among a particular group of human beings at a particular time. Having a shared model is accepting a potentially complex ultimate rule of recognition from the internal point of view: according to an attitude favoring continued cooperation consistent with the accepted model. The model is, consistent with Hart's understanding, a guide for conduct, and it provides grounds for criticizing behavior departing from it, flagging departure from the model as a

\footnotetext{
${ }^{79}$ See, e.g., HART, supra note 8 , at 116-17 (setting out as a criterion for a legal system that "its rules of recognition specifying the criteria of legal validity and its rules of change and adjudication must be effectively accepted as common public standards of official behaviour by its officials"). Of course, we might judge the set of accepted models on other grounds, including scientifically. If the accepted models all proceed from basic assumptions that the universe is fundamentally made of milk, ash, and fire, one can judge that these models are a poor fit to our lived reality, as revealed by science. But accuracy is not what we are observing when we identify, as opposed to judge, law.
} 
departure from the cooperation more generally. ${ }^{80}$ Thus the legal system gathers to itself the moral force of the underlying ties that bind the group whose cooperation is the law, however weak or strong that force might be.

For example, suppose participants share a single model that decisions of the group shall be those favored by a majority of the group, where each member's expressed preference shall be based on his or her assessment of what is best for the group as a whole. ${ }^{81}$ While they maintain disparate models of greater detail for reaching decisions, having among them different reasons for concluding one or another result is "best," they each locally accept such models for determining what is best that they locally identify as used by others. For several decisions, this appears to work, and members in the minority accept results that go against their more detailed locally preferred models. Attempts to carry into effect decisions reached only by a minority or to block decisions reached by a majority could be criticized as "illegal," because they are clearly contrary to the shared model. Indeed, participants expect such efforts would be so criticized.

But now suppose a new circumstance arises, perhaps a decision whether to construct a building. The building would disproportionately advantage one member of the group. This member announces he is voting for construction because he is the most important member of the group and that what is best for him is necessarily best for the group. The other members had accepted that members might disagree concerning what is best for the group, and they had mutually accepted a model of decisionmaking that would bind them to decisions contrary to their own views. But, reflecting on this new occurrence, each member reconsiders the minimal decisionmaking models he or she accepts and concludes that "an assessment of what is best for the group" implies an equality principle and that a model of reasons that takes no account of such a principle is unacceptable.

What the selfish member has done is not down to theoretical disagreement concerning the grounds of the group's decisionmaking. Disagreement was contemplated and expected, indeed inevitable. No, his actions are contrary to an acceptable understanding of the grounds of the group's cooperation, that minimal shared model they had believed they maintained. In light of this new experience, the members realize that the selfish member has violated a mutually accepted model of cooperation, because that model requires that no member's interests be treated as any more important than those of any other member. While this principle would not rule out decisions that confer

\footnotetext{
${ }^{80} \mathrm{Id}$. at 117.

${ }^{81}$ Note the obvious lack of determinacy here. A more detailed model might specify how best interests are to be determined. The point is that the group has mutually accepted a model under which people might differ on that question.
} 
special advantages or disadvantages, such decisions may not be grounded in reasons that identify some members as inherently more important than others.

This may sound imprecise, and that is precisely the point. The members are refining the terms of their cooperation, as they must. They cannot do the impossible and set out for all time the structures of reasoning and processing they will find acceptable in the future. There is no ultimate when it comes to reasons for decisions. All attitudes of acceptance are attitudes and thus defeasible. That being so, the validity of the things accepted is defeasible. ${ }^{82}$ Acceptance of a model depends on the scope of imagination one brings to its analysis. New uses of the model may reveal deficiencies of imagination and become cause for rejecting what was once accepted.

The basic mechanic of cooperation-each participant's accepting the locally identified models as they would apply to prevailing and anticipated circumstances-will appear more concrete once we develop a common language for describing such models and their constituent parts. ${ }^{83}$ But the legal system of a cooperative group can usually be identified as some model of the group's practice shared by its participants. ${ }^{84}$ It is necessarily indeterminate, because the model does not and cannot contain all the reasons that would be required to resolve all future cases. But it must contain, at least, an agreement to accept potential disagreement about such things, that being the essence of acceptance of an incomplete, locally identified model. Indeed, the evolution of the legal system will likely be toward the most detailed models shared by those participants with power under the rules as defined in a more abstract, accepted model.

This short discussion of basic definitions may have obscured the fact that legal systems operate not within a singular group of individuals that reaches discrete decisions but among cooperating and conflicting subgroups, affiliated with one another at various levels of remove. A key observation, though, is that the global definitions we have described and the mechanisms of cooperation so far discussed are fractal: When you examine the workings of one of its parts, you find the same structure that characterized its whole. The global system is a union of communicating institutions. Each of those

\footnotetext{
${ }^{82}$ For an interesting, short review of defeasibility in law to which the theory advanced here is congenial, see Bartosz Brozek, Law and Defeasibility, 23 REvus 165, 169 (2014) ("Defeasibility is a formal mechanism which may - but also may not - be used to model legal phenomena.").

${ }^{83}$ See Part IV, infra.

${ }^{84}$ An exception is mutual mistake where there is no acceptable common denominator. Hart would, again, not recognize such a mistaken cooperation as a legal system, there being no acceptance of a single rule of recognition from the internal point of view. HART, surpa note 8, at 116 (arguing a legal system exists only if "rules of recognition specifying the criteria of legal validity and its rules of change and adjudication [are] effectively accepted as common public standards of official behaviour by its officials"). The language of modeling permits us to understand the phenomenon of cooperation even without a unifying rule.
} 
institutions can itself be viewed as a legal system. And these institutions are themselves unions of legal systems, all the way down to the warring components of a single individual's mind. ${ }^{85}$ Describing a model of a legal system, then, is to describe models of institutions and the communications between them. We can speak with more precision if we can describe a template for such legal models, which is precisely the role of the institutions and information theory to which I turn next.

Such a template will help to show, for example, how there can be a shared model of institutional functioning among participants in an institution but, perhaps, conflicting models (even at the most basic level) between participants in different institutions. Whether such local acceptance but global conflict results in a breakdown of the legal system depends on the extent to which institutional outputs are so unacceptable to members of the institutions that cooperation between institutions fails.

\section{THE INSTITUTIONAL REPRESENTATION}

To study law is, again, to study the conceptual side of cooperation among a group. Because all understandings of cooperation are models, it is useful to create a generic scheme for representing such models. Is there a blueprint of sorts that can be used to describe most or perhaps even all legal models, one that must obviously be flexible but also illuminating? I propose here a template for models of the information-exchanging, decisionmaking institutions that compose legal systems.

\section{A. The General Model of Information Flow Through a Deci- sionmaking Entity}

I begin with a general model of causation by decisionmaking agents. The model charts information flow, from source to action, making it easier to understand the various methods of regulating human activity. It reveals.

\footnotetext{
${ }^{85}$ The human experience of a unified mind at the individual level is a product of evolution that could be otherwise. See, e.g., Peter Godfrey-Smith, Other Minds: The Octopus, the SeA, And the Deep ORIGINS OF CONSCIOUSNESS 85-87 (2016) (discussing the divided intelligences humans exhibit after surgery severing the brain's corpus callosum, the connection between the left and right hemispheres). "To some degree, unity is inevitable in a living agent: an animal is a whole, a physical object keeping itself alive. But in other ways, unity is optional, an achievement, an invention. Bringing experience together-even the deliverances of the two eyes - is something that evolution may or may not do." Id. at 87 . So too, a group's apparent unity is a contingent product of its history and practices.
} 
Decisionmaking agents receive information, process it, think about things, make decisions, and then engage in actions for which they have the necessary instrumentalities. Such actions might be further communication, or they might be non-communicative actions. These are the discrete steps in the chain of human causation, each of which could be a potential target of regulation or influence.

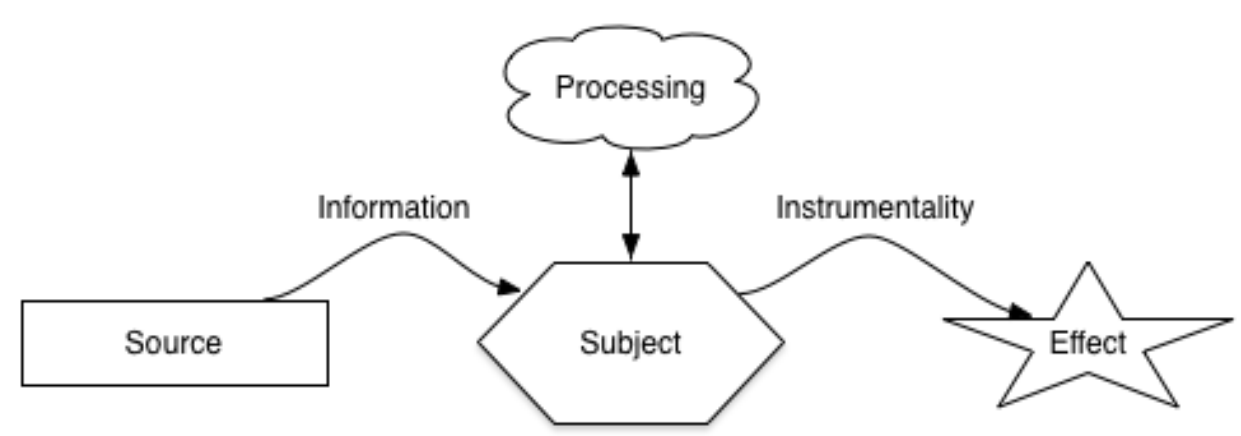

The basic assumptions here are as follows:

1. There is a physical source that produces data. This source could be a human acting intentionally or a non-intentional physical phenomenon.

2. The information produced by the source reaches the agent's senses.

3. The agent processes the information, transforming the data into mental representations that are integrated into the many trees of beliefs, reasons, and ideas the agent maintains.

4. Ideas may lead to actions if the instrumentalities necessary for such actions are available.

5. Actions cause effects. ${ }^{86}$

We have a special case of this general pattern when the output (the effect) is the transfer of information to another entity. In such a case, the instrumentality is the means of information transmission, like a piece of paper and a pen

\footnotetext{
${ }^{86}$ The basic approach here is similar to that taken by Corey Yung in an insightful and illuminating article on information theory applied to constitutional interpretation. Corey Rayburn Yung, Constitutional Communication, 96 Bos. UnIV. L. REV. 303, 311-14 (2016). The shortcomings he observes in the basic model of information leads him to integrate context and subtext, an account of which reveals relations among various of the dominant schools of constitutional interpretation. Id. at 332-39. I will adopt a similar complication of this basic model, observing that a decisionmaking institution must choose among relevant information sources and it does so cooperatively in a manner that is modeled by its participants - and, thus, in a way that is part of the institution's internal law.
} 
or a messaging application and infrastructure, and the effect is the delivery of information. We have:

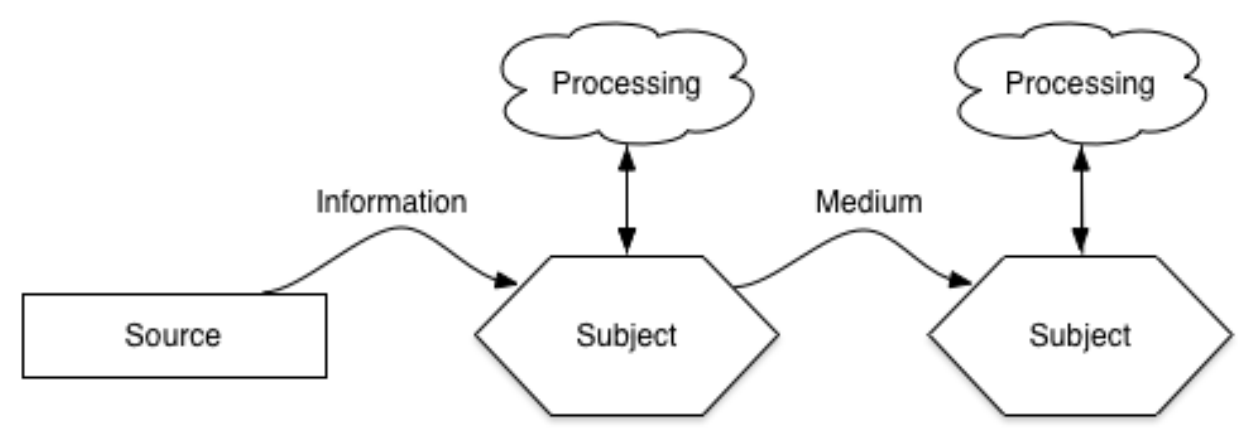

The more detailed model is useful because it reminds us of all the points at which we might endeavor to affect the process of understanding and transmission:

- sources of information,

- the conveyed informational input (acted upon by disrupting or conveying other information, whether metadata or information otherwise supportive of or critical of the informational inputs),

- human (or entity-wide) processing of informational inputs (among other things filtering available inputs for relevance, combining inputs with beliefs, reasoning, weighing, and the construction of new ideas),

- the instrumentalities of action (acted upon perhaps by rules affecting the availability and uses of instrumentalities),

- the actions themselves (acted upon by rules directly requiring, permitting, prohibiting, encouraging, discouraging, or otherwise influencing "effects").

This general description of information flow helps us to see the omnipresence of information flow in any system of regulation. ${ }^{87}$ For example, if the bad outcomes that concern us are inefficient contracts, the description encourages us to look along the chain of action, mindfully choosing whether

\footnotetext{
${ }^{87}$ Knowledge is an unusual good on account of its being, among other things, "sticky" (not practically capable of reallocation), non-rival, non-excludable. The regulation of knowledge is, for these and other reasons, an emerging, fascinating, and complex field that also subsumes some other, more longstanding understandings of regulation. See generally James Boyle, The Second Enclosure Movement and the Construction of the Public Domain, 66 Law \& ConTEMP. Probs. 33 (2003)
} 
to interrupt or redirect the information leading to the entering of such contracts, to supplement such information, to make it more difficult to complete such contracts, or simply not to enforce them.

A legal effect, like any other effect mediated by a decisionmaking entity, can be modeled by this causal flow model. Source, information, ideation, instrumentality, effect. ${ }^{88}$ A legislature, for example, receives information from multiple sources, deliberates, and produces further information. That information is itself an input into the decisionmaking of other legal institutions. To have a model of a legal system is, partly, to have a model of the relevant institutions and how information flows among them.

Suppose we have a society in which a tyrannical emperor Rex makes every decision. ${ }^{89}$ Here is a possible model of its legal system:

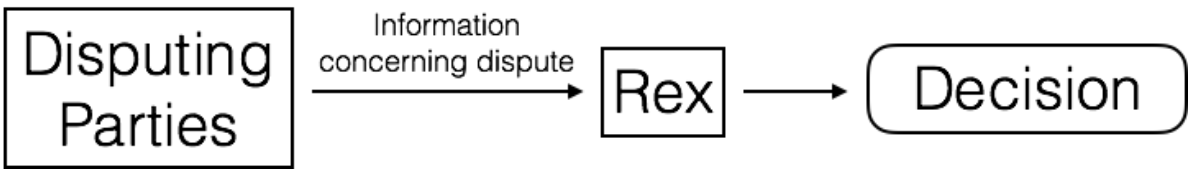

And here is what I call the "Schoolhouse Rock" model of the United States' legal system. ${ }^{90}$

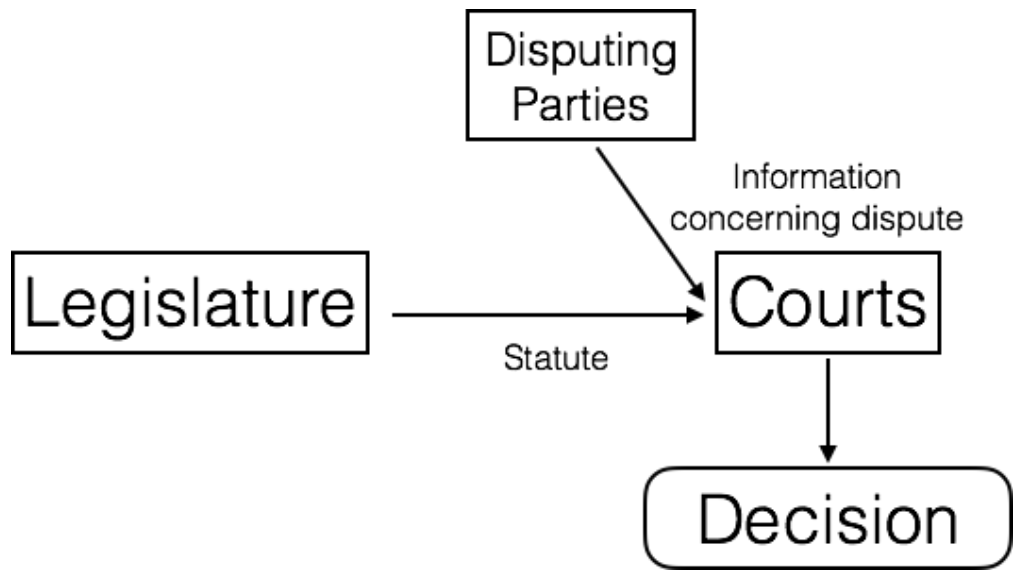

\footnotetext{
${ }^{88}$ This model adopts in the legal context many ideas of what political scientists have called Discursive Institutionalism. See Schmidt, supra note 6, at 313-17 (distinguishing the school from the rationalactor-focused new institutionalism as well as historical and norm-based approaches). Here, we have a picture of discoursing agents, constantly building and sharing ideas in a pool of inter- and intrainstitutional communication.

${ }^{89}$ Here, of course, I refer to the simple example of authority debated by Hart, Fuller, and others. See HART, supra note 8, at 52-52; FULLER, supra note 16, at 33-41.

${ }^{90}$ It is a depressing consequence of aging that "Schoolhouse Rock" must be cited, but see, e.g., http://www.schoolhouserock.tv/ThreeRing.html, if the Saturday-morning standby of the 1970s and 1980 s does not immediately leap to mind.
} 
This is not the only possible model. In fact, we may find it totally inadequate to answer pressing questions concerning the law. What if there is a question whether the President signed the bill, so that we must contain information from the Executive institution to reach a decision? Is a statute valid if the President signs a bill only passed by the House but not the Senate? What if the House and Senate pass slightly different versions of a bill? If I believe in the authority of "the Constitution," there may be some questions upon which the set of information produced by House and the set of information produced by the Senate are both critical. In those cases, a locally acceptable model of the legal system will have to take account of both institutions. And so, such model will at least contain the following schematic:

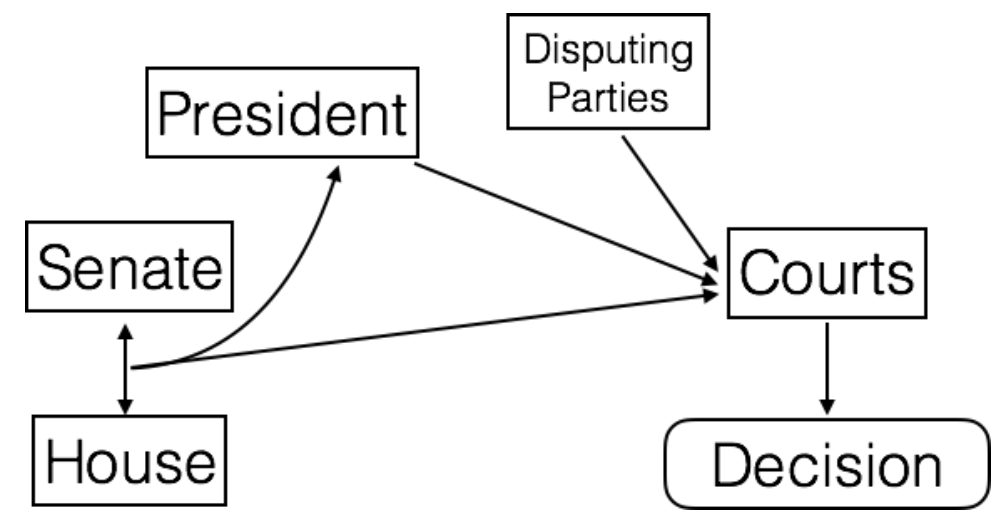

We could offer further refinements, adding administrative agencies, legislative committees, expert witnesses, juries, and more. There simply is no "true" model that is not all of reality itself. Rather, my attitude toward cooperation will follow from my acceptance or not of an idealized model, which takes account of a small set of institutions communicating in certain ways. ${ }^{91}$

The important observation here is that legal institutions operate this way, that they receive input data, process it according to internal rules, and produce output data. The participants in this information network operate on the basis of models they maintain of this network, including models that inform their own processing. ${ }^{92}$

But we do not yet have enough content in these schematic models to understand the attitudes that people maintain about legal systems. These

\footnotetext{
${ }^{91}$ More detailed and differently focused models will be deployed depending on the questions under consideration. Just as with the rest of our perceptible world, models come online to deal with the reality concerning us at the moment. See supra Part III(A), supra.

92 This "law as modeling of networks of decisionmaking institutions" theory has much in common with the fascinating psychological model of judging advanced by Dan Simon: "The theoretical core of the suggested model is as follows: legal questions are cognitively represented as connectionist networks, in which the relevant facts, concepts, principles and vying outcomes are all interconnected by means of inferences." Dan Simon, A Psychological Model of Judicial Decision Making, 30 RuTGERS L.J. 1, $122(1998)$.
} 
models contain only institutions and connecting pathways, like a diagram of a computer that contains only a schematic of chips and connections but no description of the logic of each processing unit. Such descriptions tell us only a little about how a system works. For more, we need to delve inside institutions and develop a language that describes models of their decisionmaking.

\section{B. Modeling Reasoning}

Let us take again the simple model of the legal system of the tyrant Rex. Before him all disputes are brought, and by him all resolutions made according to his then-prevailing will. To understand the legal system of this public, we might model the institutions of the disputing parties, conveying information to the institution Rex, who then conveys information concerning resolutions to those who carry out his orders. In diagram form:

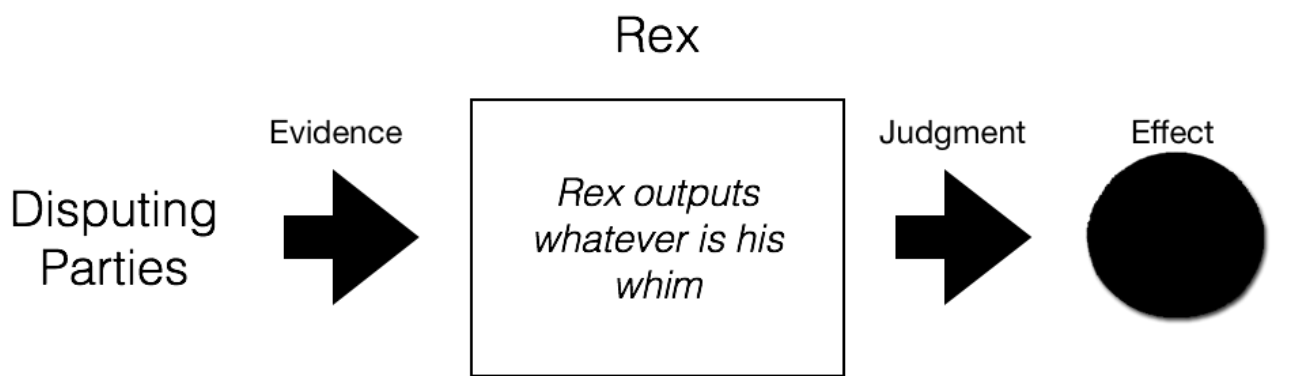

Note that this simple model answers some questions one might have concerning the law of Imperium Rexum. It may be the model I consult when asking myself who resolves disputes in the empire. When I think of what I should do when I have a disagreement with a fellow subject, I know that I must bring the dispute before Rex if I want a resolution that invokes the coercive tools of the empire itself. Other questions, though, are not answered by this model. What is Rex likely to do with my dispute? What should I argue to Rex? How should I express my argument?

To describe more fully the law of the state of Imperium Rexum, we must refine this model to describe its institutions' processing of informational inputs into informational outputs. The diagram above describes the flow of legally relevant information, but it does not explain other than superficially what the law of this jurisdiction is. Far from understanding the potential sources of theoretical disagreement within the empire or the moral principles to which it adheres, we do not know from this model what the outcome of any particular case is likely to be. Nor do we even know what information Rex will consult and to which he will apply the reasons he maintains for his 
dispositions. The model is a bit too normatively inert for most questions we might have.

What we seek is a description of the manner in which an institution connects inputs to outputs, which in the case of human beings consists of what we can simply define as "reasons." To model cooperation is to generate a simulating mechanism to stand in for the decisionmaking agents with whom one is cooperating. One needs to model their reasoning. It is this capacity for intellectual empathy that makes legal systems possible.

Let us call an institution-information model of a legal system a collection of institutions, a schematic of the informational connections between legal institutions, and, for each institution, a set of reasons that connect informational inputs to outputs. This is a schematic of the social software on which the society runs.

These institutional reason sets are not necessarily disaggregated or integrated statements of logic. Nor must they necessarily cohere. For example, the logic of the Rex institution in the above model could be the following:

- Root 1: Rex's currently prevailing desire controls his output.

○ Branch 1: Rex desires to rule for plaintiffs on days other than those with new moons.

- Further: Rex is correct concerning the phase of the moon with a probability of eighty percent.

- Branch 2: Rex desires to rule for defendants at all other times.

- Root 2: Rex rules for people with brown hair.

- Further: Rex notices hair color sixty percent of the time and is guided by moon phase forty percent of the time.

Note, too, that we could assemble Rex's reasons into hierarchical trees of reasons and that Rex might maintain incompatible trees. Rex's computational character can then be described, whether accurately or not, by a set of reason trees. Using the model, we examine an input, apply the set of reason trees, and draw conclusions concerning the outputs Rex will produce. And we can decide, if we identify this as Rex's model, whether to accept it. 


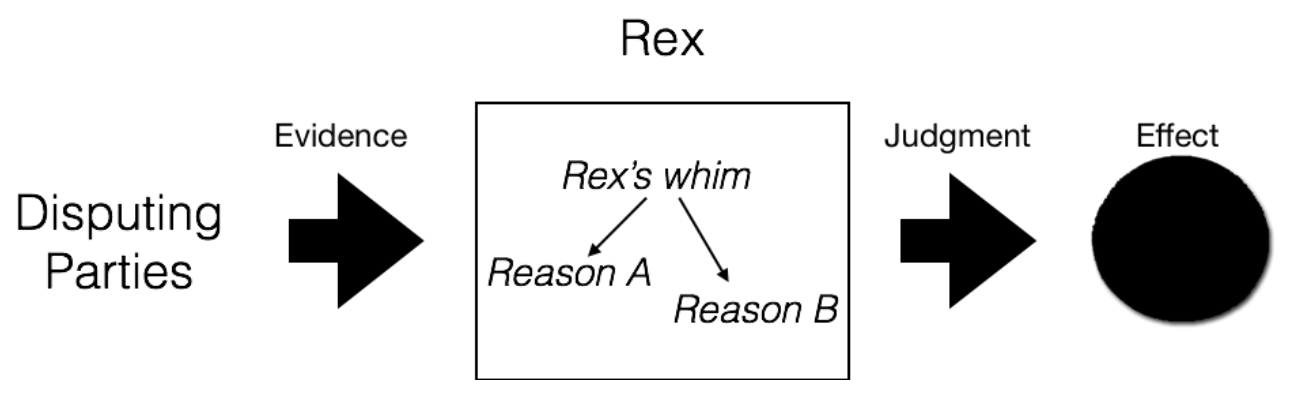

This reason tree could also be considered the internally managed set of secondary rules that control Rex's informational output, which we could call the primary rules relative to Rex. Under this model, Hart's conception of law is a special case in which the legal system is described, conceptually, as a single institution. Its reason tree is the set of secondary rules, terminating in the embedding of the content of the ultimate rule of recognition in the following reason: "Legal actors must produce information consistent with the conventionally followed ultimate rule of recognition." Alternatively, we could describe Hart's concept of law as a fixed network of information-exchanging institutions that all contain the same DNA, the chain of rules terminating in the ultimate rule of recognition.

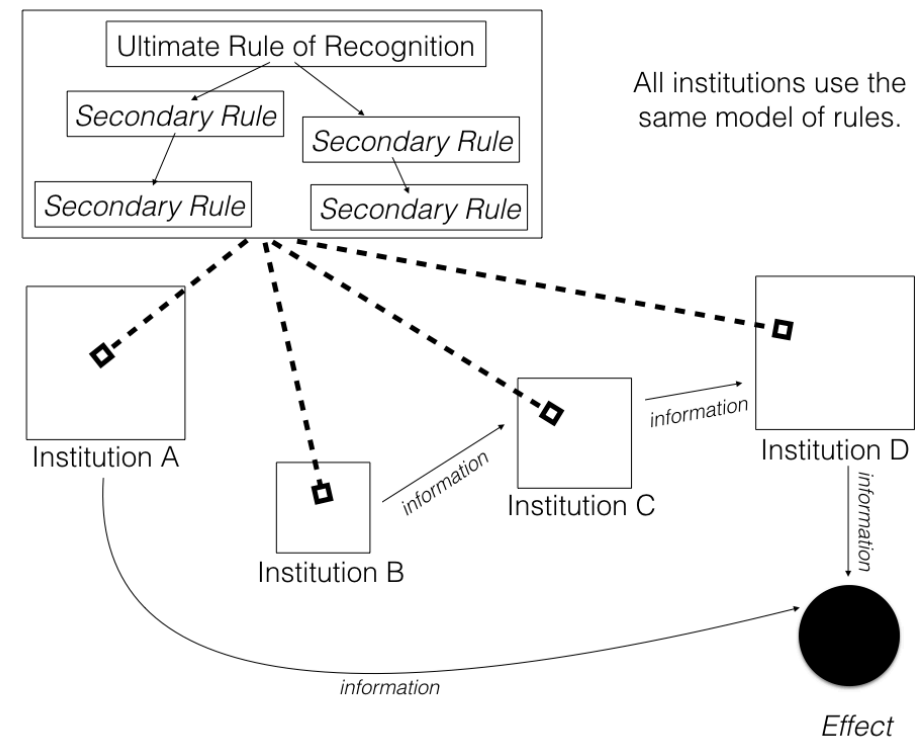

The information and institutions model generalizes Hart's model, because it understands legal systems as connected institutions that each maintain their own reason trees, and thus their own ultimate rules of recognition, the lowest-level models at which there is mutual acceptance. This permits us to see more deeply the connection between formally separate legal systems, the influence of pluralism, the nature of constitutional crises, and the role of 
claims to authority. Institutions can be perceived and may possess a self-concept as connected to other institutions, authoritative over other institutions, or members of a "system" of legal institutions. ${ }^{93}$ These connections, though, are inferred from models of the institution's reasons, in particular the manner in which and whether it takes account of information generated by other institutions. So systematicity arises from the ground-up modeling of roles by institutional participants, rather than flowing from a definition of law as necessarily implying a unifying, single rule of recognition on all the institutions in a presupposed system. We will examine this idea of "system perception" in more detail in the next Part.

Let us now consider an example, the case of the United States, and draw up a model of its legal system. Many writers seem to assume that the ultimate rule of recognition in the United States is the Constitution and that, following Hart, the institutions and rules of validity can all be derived from that rule and later actions approved under it. ${ }^{94}$ This seems incorrect under Hart's theory. Rather, the ultimate rule must be prior to the document, which, after all, is only a datum. It must be something along the lines of: "The content of the Constitution is binding on all legal actors." 95 That does indeed seem to be the social rule that is accepted as a matter of convention by courts, legislators, and executives. There is radical disagreement, however, among legal actors concerning the meaning of the Constitution. If the Constitution itself were the ultimate rule, then it would be impossible for people to disagree concerning its content and yet identify it as specifying a conventionally followed social

\footnotetext{
${ }^{93}$ The ground-up notion of institutional structure, rooted in perception and ideation, is similar to the perspective of Discursive Institutionalists. "DI simultaneously treats institutions as given (as the context within which agents think, speak, and act) and as contingent (as the results of agents' thoughts, words, and actions). The institutions are therefore internal to the actors, serving both as structures that constrain actors and as constructs created and changed by those actors." Schmidt, supra note 6, at 314. 94 See, e.g., HART, supra note 58, at 202 ("[In the United States], there is no legally unlimited legislature, even in the widest interpretation of 'legislature'; but the system of course contains an ultimate rule of recognition and, in the clauses of its constitution, a supreme criterion of validity."). Stephen Carey has surveyed and added to much more sophisticated attempts to identify the rule of recognition in the United States, in ways that map the debates among exclusive and inclusive legal positivists. Stephen V. Carey, What is the Rule of Recognition in the United States?, 157 U. PA. L. REV. 1161, 1175-83 (2009) (analyzing Kent Greenawalt's theory of a hierarchical rule, which contains content solely arising from the Constitution and content defining basic authority of the states not arising from the Constitution, and Kenneth Himma's theory of the rule as identifying validity with the interpretations of the Constitution by the Supreme Court it deems "morally best"). Carey proposes a more complex and inclusive positivist version of the rule that derives from the strengths of earlier efforts. $I d$. at 1192-94. A more careful dive into these debates and their fit with the modeling theory will have to be left to future work.

${ }^{95}$ Perhaps the Supremacy Clause states the ultimate rule, self-referentially declaring the document containing it to be the supreme law. See U.S. Const. art. VI. I would still argue that the ultimate rule is the fact that the clause is followed. That is, the ultimate ground for criticizing an official for departing from the content of the Constitution, is that he or she has violated an obligation to be bound by the content of the Constitution, not that he or she violated the Constitution.
} 
rule through its content. ${ }^{96}$ After all, without agreement, the content would not be conventionally followed. The modeling theory helps us to see that cooperation can exist based on the contingent social fact of acceptance of models of cooperation, even without specifying an ultimate rule in minute detail or even a rule that is coherent in all its possible applications. That there are serious objections to an ultimate rule does not negate the fact that participants have mutually accepted it at a high level, with those objections perhaps one day disrupting the cooperation if the right input data reveals problems.

A picture of the institutions-and-information model looks quite different from Hart's, even though the theory maintains his core ideas:

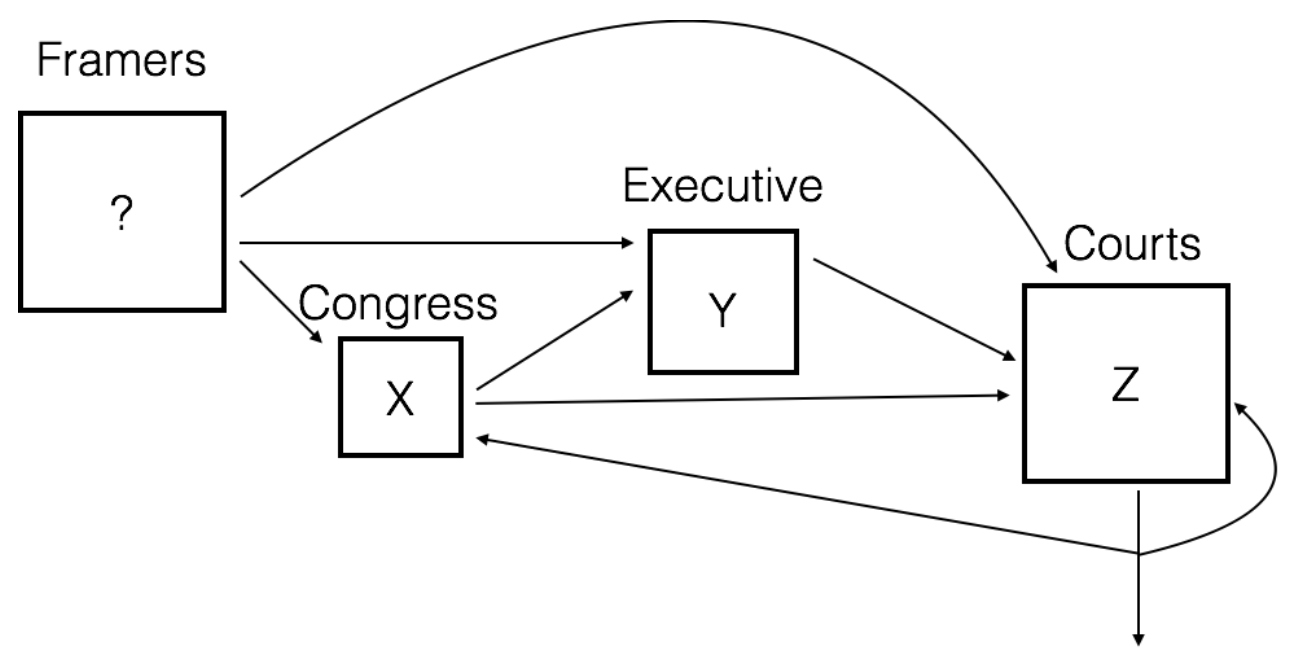

Right away, without thinking more about what it means to assert such a model, we see that this approach allows us to take account of warring secondary rules and dynamically to model at least some theoretical disputes over time. The Supreme Court and the Congress could be operating under separate reason trees that take different views of the meanings and authoritativeness of congressional data or even the relevance of various other institutions.

We also see that an institution's reasons (or secondary rules) could follow entirely from the commands of other institutions, be influenced by other institution's data, or be independent. There may be some institutions whose processing is so constrained by the output of other institutions that we feel

\footnotetext{
${ }^{96}$ This is the essence of Dworkin's criticism of Hart's positivism, that it cannot account for theoretical disagreement about the identification of law. See, e.g., DwORKIN, supra note 7, at 1-7. As my theory shows, this criticism fails because it does not account for the fact that agreements to cooperate do not necessarily entail agreements to agree on output. Agreements to cooperate are captured by acceptance of higher-level models (say that the Constitution controls and its meaning is determined by the majority vote of the Supreme Court) and are possible even in the face of strong disagreement concerning the proper form of lower-level models (that, for example, the Constitution's meaning is governed by the reasons of another institution, say the Framers as they gave those reasons to their principals, which reasons can be uncovered by references to contemporaneous dictionaries and the texts they wrote).
} 
they are unnecessary even to consider in a model of the legal system. Perhaps, depending on a system's rules, in jailors we find an institution that issues commands (at least those commands we are interested in modeling) that are completely determined by the output of courts. If this is so, then we can understand the legal processes that include them without modeling them as independent institutions and sources of information. Our mental model can omit them if our questions do not go to any matter on which their reasoning could have an effect.

But this observation also points the way to a difficulty and an opportunity. It is true that we do not normally account for the independent decisions of jailers in our mental models of legal systems. Are such decisions completely constrained? An entire genre of legal scholarship is driven by what we might call the identification of the missing institution. The basic claim of such an effort is that an important class of questions about the legal system cannot be answered without including the missing institution into the model. Indeed, the "Schoolhouse Rock" model does not include administrative agencies. While we might be able to answer some legal questions without such institutions, other questions will be unanswerable without taking account of them. $^{97}$

And so we are reminded that all our models are approximations of an ongoing social practice. Like all models, they are attempts to capture important features of some reality in order to answer particular questions. Does this fact, that no legal system model we generate is entirely descriptive of "the real" legal system, mean that the information and institutions theory of legal systems fails? No, it means only that instances of modeling are incomplete. But such models are, I claim, integral to a correct understanding of the social practice that is law. My thesis is that we generate models of cooperation on demand, at different scales, and from different perspectives.

Some of the long-burning questions of jurisprudence are answered by what we have observed so far. For example, the connection between law and

\footnotetext{
${ }^{97}$ The modeling framework introduced here implies a broader categorization of legal scholarship that I leave for future work. In addition to identifying a missing institution (Nestor M. Davidson and Ethan J. Leib, Regleprudence-at OIRA and Beyond, 103 GEO. L.J. 259, 274-94 (2015) (pointing out the importance of including the Office of Information and Regulatory Affairs in any model of administrative action), one can critique the informational connections between them (Aaron-Andrew P. Bruhl, Hierarchy And Heterogeneity: How To Read A Statute In A Lower Court, 97 ConNELl L. REV. 433 (2012) (suggesting that the reason structure of statutory interpretation should be different between lower courts and the Supreme Court and thus that different courts should examine different sorts of information when answering ostensibly the same question)), argue for alternative intrainstitutional reason trees (the most common form of scholarship), examine legal output to reconstruct reason trees (to argue, for example, they differ from their characterization in opinions or that they fail to yield to the reasons of other institutions, as in the classic critique in Roscoe Pound, Law in Books and Law in Action, 44 AM. L. REv. 76 (1910)), and illuminate disputes among legal actors by showing the differences between their implicit models.
} 
morality, the non-distinction between legal and non-legal cooperative systems, and the possibility of theoretical disagreement even if law can be identified as arising from social facts alone. We will take an initial but more systematic look at those questions in Part V, but it will help if we first examine more closely two principles that have a common basis.

First, we must understand that reason trees have an internal structure, that theoretical disagreement concerning proper legal output can occur at different levels of secondary rules, and that all reason trees ultimately rely on a primitive assumption or assumptions (while also silently omitting an unimaginable number of other assumptions implicit in the semi-logical glue between assertions). Second, we need to appreciate that legal practice consists not in executing a particular model of law but the cooperation of individuals under individualized models of law, where an empirically sufficient subset of participants accepts a common model, despite disagreeing on elaborations of that model. Law is thus something that can be perceived externally, observing that others are cooperating, and accepted internally, accepting locally identified models. And so now I turn to a consideration of the internal perspective, a model of rules as institutional actors construct them.

\section{A Model of Rules in an Institutional Setting}

The secondary rules that govern institutional action come in qualitatively different categories and can be ordered in ascending levels of generality. A newly minted first-year law student often feels as though he or she has embarked on a colossal endeavor to build the right model of "the law" that contains all of the rules in their proper place. But a critical leap is made when the student begins to perceive both the absence of the list and still some order in the sea of possible justifications for decisions - (a) that some sorts of reasons go together and (b) that some reasons lead the decisionmaker to invoke, take account of, or ignore the reasons of other institutions. They then begin to perceive the cooperative web of law in its truer complexity and that disagreement can arise without wrongness.

I will discuss these levels in order, but, to summarize, there are four: (1) dispute resolution, (2) reason choice, (3) institution choice, and (4) institutional theory. ${ }^{98}$ For each level, there is possible disagreement over the choice

\footnotetext{
${ }^{98}$ In an earlier version of this schema, I described these levels somewhat differently and was focused a bit more on pedagogy than on theory. See Christian Turner, Leveling Up, available at $\mathrm{http} / / / \mathrm{www}$.hydratext.com/blog/2014/7/25/leveling-up. The simplified version is a useful framework around which I organized a course in Legislation and Regulation for first-year students.
} 
of resolving reasons and over the application of the chosen reasons. ${ }^{99}$ Viewed within a single level, such disagreement can therefore appear either theoretical, being a dispute over grounds, or practical, concerning a potentially falsifiable application of agreed-upon reasons.

What is more, categorizing the reasoning structure this way exposes the senses in which an institution's decisionmaking can be viewed as primitive or systematized. Hart's distinction between sophisticated legal systems and what he called primitive legal systems (those lacking secondary rules of recognition, change, and adjudication) is both too broad and not broad enough. ${ }^{100}$ All legal systems are ultimately primitive, but they can be so at different levels and on different questions. To see the sense in which that is so, let us first examine the sorts of decisions and disagreements reached at each level of institutional reasoning. I imagine in what follows an institution that believes it is tasked with reaching a decision. Its participants, each possessing a model of the institution and accepting some identified models of other participants, now work together to do so. Our analysis will build the following chart, identifying different levels at which they might disagree and, at each level, whether their disagreement is theoretical (concerning reasons for a conclusion) or empirical (concerning how the reason applies to the question at hand).

\begin{tabular}{|l|l|l|}
\hline Level & Reason (Theoretical) & Application (Empirical) \\
\hline $\begin{array}{l}\text { 1: Dispute } \\
\text { Resolution }\end{array}$ & $\begin{array}{l}\text { Justification (theoretical at } \\
\text { the level of fact) }\end{array}$ & Decision \\
\hline $\begin{array}{l}\text { 2: Reason } \\
\text { choice }\end{array}$ & $\begin{array}{l}\text { Reason for choice of justi- } \\
\text { fication (theoretical at the } \\
\text { level of policy) }\end{array}$ & Justification identification \\
\hline $\begin{array}{l}\text { 3: Institution } \\
\text { choice }\end{array}$ & $\begin{array}{l}\text { Reason for institutional as- } \\
\text { signment (theoretical at the } \\
\text { level of organization) }\end{array}$ & Institutional assignment \\
\hline $\begin{array}{l}\text { 4: Institutional } \\
\text { theory }\end{array}$ & $\begin{array}{l}\text { Theory of institutional as- } \\
\text { signment (theoretical at the } \\
\text { level of cooperation) }\end{array}$ & Reason for assignment \\
\hline
\end{tabular}

\footnotetext{
${ }^{99}$ There is a similarity between the levels of institutional reasoning I map here and the levels of generality of ideas in discourse identified by political scientists. "The first level encompasses the specific policies or 'policy solutions' proposed by policy makers. The second level encompasses the more general programs that underpin the policy ideas. ... . At an even more basic level are the 'public philosophies,' 'public sentiments,' or 'deep core' . . . Schmidt, supra note 6, at 306 (citations omitted) .

${ }^{100}$ HART, supra note 8, at 91-94.
} 


\section{Level One: Deploying Reasons}

At level one, the legal analyst examines the informational inputs concerning the decision to be made and makes a decision applying some reason. Put slightly differently, the level-one practitioner is able to seize upon reasons to resolve a case.

For example, suppose a person demands payment from a business owner after being struck by a barrel that somehow fell out of the business's secondstory window. ${ }^{101}$ The level-one practitioner, hearing these facts and various but contradictory sets of reasons for resolution urged by the two sides, concludes the plaintiff should win. Perhaps he or she decides (1) that negligent conduct that somehow directly (meaning, as far as the practitioner can tell, not too indirectly) injures someone creates a duty of compensation and (2) that negligence should be found even when there is no direct information concerning the negligent actions themselves if the consequence of the unobserved actions can hardly be imagined to occur without negligence.

Armed with these reasons, the practitioner then decides that barrels do not fall out of second-story windows without someone's gross inattention and that there was no explanation from the business owner that would suggest otherwise. This being so, the injury directly resulted from the negligence of the business owner. The level-one practitioner then concludes that the legal system should order the business owner to compensate the victim.

Note that there is an argument here concerning how the reason chosen processes input data into output data. Without that, our practitioner would be an actor, not a decisionmaker. Our goal in understanding legal systems is to understand decisionmaking pursuant to cooperation, not unreflective action that cannot be modeled. There is no argument, however, supporting the practitioner's particular choice of reason. Much lay argument concerning law operates at level one. A proponent of a result will cite a reason but not reasons for choosing that reason.

Another level-one practitioner might disagree with the result in the barrel case, not with the reasons given but with how the reasons apply to the input data. Maybe she believes that barrels often fall out of windows for reasons beyond the practical control of any human. Agreeing on criteria of liability and on their manner of proof, our lawyers disagree concerning how they apply to the input facts here. This is level-one application disagreement, applying the same software to the same input data and yet arriving at different outputs.

Suppose, however, that another level-one practitioner responds that negligence must always be proved and never only inferred and that the plaintiff

\footnotetext{
${ }^{101}$ The example I use here, obviously, is a familiar torts case. Byrne v. Boadle, 159 ENG. REP. 299 (1863). Its decision more or less mirrors the level-one analysis given here and is thus primitive when viewed from level two.
} 
should lose for that reason, whatever the empirical reality of barrels and windows. This level-one disagreement is theoretical, as it involves disagreement concerning the grounds for the level-one decision. Our dispute now concerns the theory of the decision. ${ }^{102}$ If the argument does not somehow rise above the conclusory citation of disparate reasons and reasoned application to the facts, then here at level one we will remain.

\section{Level Two}

If practitioners' arguments for their preferred reasons for an outcome are only conclusory - $A$ argues for outcome $\mathrm{X}$ because $\mathrm{R}$; $B$ argues for outcome $\mathrm{Y}$ because $\mathrm{S}$ - then we do not have an argument at the level of reasons, a level-two argument. We have only a disagreement that appears primitive to those seeking to understand the dispute better. A legal system that settles on $A$ 's side has made a choice concerning the reason for decision, but its choice is primitive from the vantage point of level two, there being no reason supporting its choice among competing reasons that could be used to resolve the case. $^{103}$

Case after case may be considered in more or less this level-one way, though. The rule here is "this." A finder of apparently lost property should be declared its owner as against all the world except the true owner who lost it. ${ }^{104}$ What about this other situation? Well there it ought to be "that." A finder of mislaid property does not prevail against the owner of the premises on which the property was found. ${ }^{105}$

At some point, practitioners are bound to ask themselves what sorts of reasons should be used to resolve cases. What reason, for example, do we have to arrive at a different rule for cases of lost property than we do for those of mislaid property. Strong-willed jurists may demand of each other more than ephemeral attachments to reasons to resolve particular cases. They will seek to understand better the set of reasons to be deployed. And perhaps they will argue among themselves about what constitutes a good reason and what

\footnotetext{
102 This distinction between disagreement at the level of theory and at the level of application, which we shall see replicated at each level of analysis, is similar to and indeed inspired by Dworkin's distinction between propositions of law and grounds of law. See, e.g., DwORKIN, supra note 7, at 4-6; see also Scott J. Shapiro, The "Hart-Dworkin" Debate: A Short Guide for the Perplexed, in RonALD DwORKIN 40-41 (Arthur Ripstein ed.) (2007) (giving a crisp and lucid summary of Dworkin's attack on positivism from theoretical disagreement).

${ }^{103}$ A system that is primitive at level one is one that acts without reason and is therefore not a decisionmaking entity at all. It acts but does not decide.

${ }^{104}$ See, e.g., Armory v. Delamirie, 1 Strange 505; 93 E.R. 664 (Court of King's Bench 1722) (deciding just such a case by stating but not justifying this level-one reason).

${ }^{105}$ See, e.g., McAvoy v. Medina, 93 Mass. (11 Allen) 548 (1866) (deciding that mislaid property should be treated differently than lost property in this respect but also moving into level two by citing precedent as a reason to choose that rule).
} 
sort of reason is not so good. They will then develop commitments to reasons for choosing among level-one reasons.

Having reasons for selecting the reason to apply to reach a decision is the domain of level two. Our argument at this level can be, as with the first level, theoretical or only about application. Here, though, our theoretical argument concerns what theory we should use to evaluate possible level-one reasons, and our applicative argument concerns the application of a given theory to select a level-one reason.

At this level, instead of seemingly plucking reasons from the ether and forming opinions about case outcomes, we are interested in the more general calculus of reasons that we will use to resolve cases. Is a concern with economic efficiency compatible with a belief that law should advance a particular conception of virtue ethics? Are there domains in which the two are compatible but other domains in which we must choose, somehow, which theory to bring to bear, and with it a concomitant cascade of reasons we will use at level one to decide cases. When we argue among ourselves about such things, we are engaged in theoretical, level-two argument.

In the barrel case, should it matter what the social utility of the business's product is and how liability might interfere with its mission? What if the business's products are extremely useful to some portion of the population but others think the business evil? (Maybe it is building weapons that some believe critical for national defense and not immoral for that reason but that others believe is inherently immoral because of the particular way it maims.) Should the degree of societal support for the business matter? Is there too steep a price in departing from the uniform view of the cases in situations that can be abstractly framed as "injuries proximately caused by negligence," or would it be sound to carve out a social necessity defense?

Here, at level two, we study the law not by cataloging its "rules" in situation after situation, mastering some list of reasons bound to specific factual patterns, but by more directly studying the reasons that seem to count and understanding why those that do not do not. Our investigation will cover different approaches that contain within them sets of reasons: economic efficiency, distributive justice, the problems of natural monopoly and collective action, the problem of informational asymmetries and more general imbalances in market power. At level two, our sophistication is such that we can even bring understanding to areas of the law we have not yet formally studied, because our theoretical commitments can generate level-one rules on demand. We can begin to predict the kinds of arguments that will be made on each side without having to read them first. This, obviously, is a critical skill for an advocate. 
If the institution in fact argues at level two, it maintains a mechanism for legal change that is within the law of the institution, rather than an avulsion by fiat. It provides a means, in fact the only means, to predict what the law will be in new cases. The level-one reason, or rule, that will resolve a new type of case will de derived from level-two theoretical commitments. This is indeed how our courts work and why knowledge solely of the socalled "black letter law," the list of level-one reasons, is so infirm.

Theory is the most important part of the dogma of the law, as the architect is the most important man who takes part in the building of a house. The most important improvements of the last twentyfive years are improvements in theory. It is not to be feared as unpractical, for, to the competent, it simply means going to the bottom of the subject. ${ }^{106}$

At level two, our theoretical arguments concern how we should decide what reason to use to resolve cases. If we agree on that, then we might still disagree what that agreed-upon commitment implies. For example, we might all be thoroughgoing normative law and economists, committed to designing law to satisfy exogenous preferences and to the general validity of the rational actor model. Yet, we might still disagree on how to apply that level-two reason to arrive at a level-one reason (or rule) that can resolve a case challenging, say, a rent control ordinance on due process grounds. Our level two disagreement, just like that at level one, can be at the level of theory or application.

\section{Level Three}

Despite our new-found confidence in understanding the different levels at which we can argue, we occasionally run into cases where the theory for resorting to the particular reasons to decide cases are of a type unlike the others. These are cases in which, whatever the rationales could be for reaching any given level-two conclusion, there is a reason not to do so: that this decisionmaker, this institution, is somehow the wrong one for the task of reason-choosing in this case. Like a child first realizing that other people also have thoughts and feelings and exist within a larger community of thinking and feeling beings, at level three the institution recognizes its place within a system and asks which institution's level-two reasoning should be consulted to arrive at a rule for decision.

And so, perhaps, in our barrel case, our tribunal has never before found negligence and ordered compensation when the specific actions constituting

${ }^{106}$ Holmes, supra note 13 , at 477. 
negligence have not been described. We might believe that whether to recognize and rely on reasons that would accomplish that task should be left not to the tribunal itself but to another institution, perhaps the legislature. That is our level-three conclusion, which will lead us to channel the level-two reasoning of the legislature, not our own.

Why? What is our level-three reason for reaching that level-three conclusion? Maybe we believe that allowing courts to find negligence without forming judgments about exactly what happened will lead to decisions to create categories of industrial output that are always subject to compensation obligations when they cause injury, without regard to the internal considerations of cost and benefit that a plaintiff would otherwise have some responsibility to ferret out. Judges, acting case by case, might not appreciate the effects of those categorizations, making it too easy to bring lawsuits that have a chance of winning, and creating far too much social cost. Maybe broadbased hearings, across multiple industrial sectors, would be wise, and maybe the information thus adduced would counsel a more targeted solution to the problem of accidents that happen as a result of complex industrial processes.

This is a level-three argument for our conclusion that the legislature's theory of presumed negligence should control, and, by making it, we engage a more expansive model of the legal landscape that includes other institutions and their reason trees. The simple model that has information concerning a dispute flowing into the legal system and back out again after decision (Dispute $\rightarrow$ Legal System $\rightarrow$ Resolution) is too simple to describe the sorts of considerations we think appropriate in cases like this one. A legal system is not just one decisionmaker, but many, with information flowing among them. And level-three legal reasoning concerns not just sifting through the reasons that will lead ultimately to case outcomes but to giving a reason to assign that level-two task to a particular institution within the legal system. This is a question for the legislature. This one is for the courts. This is for an administrative agency. Those are conclusions about institutional assignment, and once we begin to speak in terms of why we might wish to make such assignments, we command a much more sophisticated understanding of legal systems. Now the decisionmaker considers whether it must apply its own reasons (in which case level two would suffice) or whether it must defer or completely yield to the reasons chosen by others. The decisionmakers must now identify, judge, and accept or reject models of the legal system that include institutions beyond their own, together with the informational content and models of reasons flowing within and from those other institutions. It is a level-three theory that gives literal shape to the institutions-and-information models of legal systems we have identified.

If we each agree on the reason that should govern an institutional choice, competency or precedent on decisional hierarchy, say, but disagree on the 
output of that reason, then, as at lower levels, we have applicative disagreement. What if we disagree about the reasons that should govern the choice of institution whose level two reasoning should apply? Here, we arrive again at a theoretical dispute.

We have arrived also at a new ground from which lower level disputes appear primitive. From here, level-two theoretical disputes are primitive, possessing no ground of correctness. The level-three theorist sees that ultimately "ungroundable" level-two argument is inevitable. The choice of what to do and why is, ultimately, political in this sense. It is a matter of choice. But this level-three theorist approves or disapproves the legal decision based on the identity of the institution assigned the ultimately political task of level-two argumentation.

Debates over the proper interpretive theory for statutes, constitutions, contracts, and other documents can be understood, and I believe are best understood, as disagreements about the proper level-three theory. They concern distinctive models of the relevant portion of the legal system and of institutional reason trees. A theory deriving meaning from original intent, for example, is a model that recovers reasons for decisions from the reasons of the promulgating institution at the time of promulgation. A more general deference model might yield to the reasons of that promulgating institution but as it is now constituted. An original public meaning originalist finds authority in the reasons the document's original audience, a new box in our legal model, would identify in that document. Textualism is a method that might be intended to approximate, in a "least error" or second-best sense, those likely reasons. ${ }^{107}$ All of these involve some channeling, some effort at the adoption of the level-two reasoning of another institution, whether past or present. Obviously, the institution could also use documents or other output from within its own system of level-two reasons, generating rules of a decision from that combination, yielding a form, but not the only form, of living

\footnotetext{
${ }^{107}$ I leave for future work more precise and comprehensive translation of the various modes of originalism and of other interpretive theories into the models of legal systems as I set them out here. The most careful mapping and argument concerning originalism is probably Lawrence Solum's Semantic Originalism. Illinois Public Law Research Paper No. 07-24 (Nov. 22, 2008), http://ssrn.com/abstract1/41120244. In short, Solum lays out various claims concerning the possibility and desirability of channeling original meanings to decide contemporary questions. His Fixation and Clause Meaning Theses are arguments at level three. They are intended to identify the reasons one can recover from a communication and thus speak to the possibility of a legal system model through which a court can recover the reason trees of historical institutions. Id. at 2-5. The arguments for Fidelity Thesis, that we should in fact, choose historical institutions (promulgators, audience, or combination) at level three, is a level-four argument, the sort described next. Id. at 151-157 (in which Solum "survey[s] the reasons that judges, officials, and citizens might have for adopting the attitudes and duties implied by fidelity"). Solum details overlapping theories for preferring originalist reasons for using the originalist model. An understanding of interpretive theories as equivalent to institutional models, again, has much in common with Corey Yung's intriguing work. Yung, supra note 86.
} 
constitutionalism, for example. Indeed, the choice even whether to be bound by the U.S. Constitution is a level-three choice.

In all this, as with the other levels, the legality of a participant's resort to a particular theory is identical with, and nothing more than, the group's acceptance or not of the model she has chosen. Whether the system tolerates disparate interpretive theories is a matter of the acceptance of those theories, despite disagreement. It is possible to imagine a supreme group of judges, some of whom make arguments that cite reasons arising from a constitution and some of whom cite only "common sense," publishing opinions and otherwise getting on with their business despite their disagreements. They have mutually accepted identified models with which they disagree. But among a different group, one that minimally accepts level-three reasons that $d o$ identify a particular constitutional source, one can easily imagine an end to such cooperation - and the beginning of civil conflict - when a participant rejects that source and refuses to go along. The others would decry the participant's actions as illegitimate and illegal. Perhaps he or she is then removed by the legal decision of this or another institution. The point is that cooperationdisrupting disagreement can occur at this level or any other. Cooperation implies mutual acceptance of identified models. An interpretative commitment is just a model containing level-three reasons. And so the permissible bounds of interpretation are no more and no less than the set of tolerable models.

\section{Level Four}

Once we have come this far, it is obvious there is yet at least one more level to attain. After all, once we say that we should ask what reason we have to assign a decision to a particular institution, it is plain that we could have reasons for choosing among competing such reasons. And so level four is attained upon recognizing that much of the work in law, and much dispute that seems bound up with substance, arises from disputes concerning the proper reasons to use when deciding on institutional assignment. Why should this institution rather than that make the irreducibly political choice our cooperation requires? Should we channel the institution most competent in this field, most representative, best resourced, most accountable in the short term, most accountable in the long term, or most likely to account fully for costs and benefits? Or should we defer entirely to the institutional author of information we otherwise deem relevant? Each is a possible level-three reason. We have come to level four when we argue over and decide among such reasons.

For example, people disagree how courts should treat statutes, constitutions, contracts and other putatively authoritative documents (whether to confine their attention to portions of the text, whether to look at any of a number 
of dictionaries, whether to consult legislative metadata concerning the document, whether to infer purposes and to aid those purposes, etc.). These disputes are, at bottom, disputes about what courts are and what legislatures and other lawmakers are within the legal system. Those constitutive questions can be identified with the reasons an advocate has for believing particular sets of reasons should govern decision of the "who" question.

Justice Scalia believed that conservation of systemic, democratic legitimacy is an overriding desideratum in developing theories of assignment and that unelected judges achieve legitimacy only by channeling the policies (the level-two decisions) of representative bodies and not by choosing their own. ${ }^{108}$ This is because legitimacy arises primarily from more or less direct and immediate accountability to the people. Those who disagree with him have different level-four theories of assignment. They may believe, for example, that legitimacy is important, but it is (a) achieved in part by pragmatic decisionmaking and not only by deferring to popularly elected institutions or perhaps (b) actually diminished by clothing decisions in illusory certainty and, instead, advanced by candor concerning the uncertainty of, say, constitutional or statutory meaning. 109

If there is no mutually agreed-upon model of level-four reasoning within the institution, then the theoretical disagreement at level four is primitive. The cooperation continued between Justices Scalia and Breyer on account of acceptance of one another's models, not agreement.

If one member cites reason $\mathrm{R}$ for choosing institution $\mathrm{X}$ 's level-two work and another cites reason $\mathrm{S}$ for choosing institution $\mathrm{Y}^{\prime} \mathrm{s}$, we again have a primitive argument, viewed from level four, as we did with unresolved theoretical arguments at lower levels. Our own constitutional law is primitive in the sense that judges have discretion over theory choice at level four that is canalized only to the extent their stated theories are accepted by others and that their down-level conclusions fall within acceptable boundaries. Because the Constitution does not include provisions dictating how it should be inter-

\footnotetext{
${ }^{108}$ While his jurisprudence is replete with level-three conclusions and level-two arguments derived from textualist interpretations, Justice Scalia's fullest level-four argument for public-meaning originalism and, by extension, textualism can probably be found in his academic work. See Antonin Scalia, Common-Law Courts in a Civil-Law System: The Role of United States Federal Courts in Interpreting the Constitution and Laws, in A MATTER OF INTERPRETATION: FEDERAL COURTS AND THE LAW 3, 9-25 (Amy Gutmann ed., 1997) (arguing for textualism from a principle of democratic accountability).

${ }^{109}$ Both of these critiques appear in Richard Posner's review of a later textualist manifesto. Richard Posner, The Incoherence of Antonin Scalia, THE NEw RePuBlic (Aug. 24, 2012), at https://newrepublic.com/article/106441/scalia-garner-reading-the-law-textual-originalism (reviewing Antonin Scalia and Bryan Garner, ReAding LaW: The InTERPRETATION OF Legal TeXTs (2012)).
} 
preted, it is plainly open to theoretical argument concerning the right informational model to use to decide questions arising under it. ${ }^{110}$ Judges will find no further uncontroversial "secondary rules of recognition, change, and adjudication" that will identify the correctness of their level-four theories or indicate the legitimacy of a change to them or application of them.

There are obviously many potential elements of a level four theory. The point is that once we begin to discuss at this level, we can sometimes become clearer about what our actual disagreement concerns, where the irreducible and ultimately political judgment about control must lie.

\section{The Monopoly Example}

Returning to our Monopoly players, ${ }^{111}$ we can now see their dispute as an evolving state of the players' modeling their cooperation and judging those models. They may begin by mutually accepting a locally identified model of nothing more than themselves, as a group, maintaining a level two rule that disputes will be resolved by the reasons contained in the rulebook that defines their game. Immediately upon encountering an unfamiliar rule, the auction

\footnotetext{
${ }^{110}$ See William Baude, Is Originalism Our Law?, 115 Colum. L. Rev. 2349, 2351-53, 2403-07 (2015) (arguing that originalism, and thus the model of the legal system to which it corresponds, is correct using a level-four theoretical argument concerning conventional interpretive practice but acknowledging other arguments that would support other models); Cass R. Sunstein, There Is Nothing that Interpretation Just Is, 30 CONST. COMMENT. 193, (2015) ("If the founding document set out the rules for its own interpretation, judges would be bound by those rules (though any such rules would themselves need to be construed). But the Constitution sets out no such rules. For this reason, any approach to the document must be defended by reference to some account that is supplied by the interpreter."); Phillip C. Bobbitt, The Age of Consent, 123 YALE L.J. 2334, 2372 (2014) ("[T] here is no hierarchy of modal forms but rather than this being a cause for despair, it opens up a space in constitutional decisionmaking for the role of the individual conscience.").

Consider an example Baude cites as a hard level-four case. Suppose we know that an originalist approach, on account of the low-quality level-two reasoning of the institution that would be channeled as originally authoritative, will lead to decisionmaking as irrational as if "all judges [were] openly decid[ing] cases on the basis of astrology." Baude, supra, at 2349. Would the conventional, positivistic duty Baude identifies to be originalist yield to broader commitments to minimal rationality in that extreme case? The realistic theory of modeling advanced here helps us to see how that might be so. Originalism implies a model that can be accepted and argued for at various levels, where acceptance almost certainly arises from a constant simulation of potential cases and subsequent affective and logical reaction by those considering such acceptance. Irrationalism as deep as astrology would certainly cause a mostly rational participant to decide that his or her level-four theory must be more complicated than "originalism" and must include limits - that originalism was a means to a broader end and that those means only go as far as the ends are advanced. This only shows the difference in aim that Baude and I have. I seek an explanation of the phenomenon of legal systems and as systematic a way to understand them as reality allows. Baude makes a normative, level-four argument for a particular model, but he acknowledges that other models are possible. Sunstein and Bobbitt address themselves to the fact that our constitutional law is primitive at level four, meaning that a model of the legal system that animates an interpretive approach may be adopted and accepted but will never be provably correct.

${ }^{111}$ Part I(B), supra.
} 
rule in our example, our gamers diverge. Their disagreement concerns whether to hold an auction. But, in fact, it goes to how that question should be answered. One player revises his model, because he does not accept the reason prescribed in the rulebook. They have a very practical disagreement at level one, because they favor different decisional outcomes. But there is theoretical disagreement at level one: they do not agree whether the auction rule should determine the result. One says an auction should be held because the auction rule is part of the game. Another says no auction should be held because the auction rule is not a part of the game.

Moving to level two, knowing that our players have selected different reasons at level one, we might wonder whether they have done so based on differing theories or on differing applications of the same theory. Here, their difference is theoretical: One cites the instruction book as authoritative, and another cites the customary manner in which "people" play the game. Those theories might be further justified by appeals to cheap coordination, to continuity of a local gaming social practice, or any other such grounds. Whatever the bottom of the position of each gamer, there is theoretical disagreement among them at level two. They do not agree on the grounds for determining whether the auction rule is a part of the game.

If one player believes that the group should yield to the host's choice of rule and another believes that they should yield to the inferred intentions of the game's creators, then there is disagreement at level three. At this level, they have in mind not just different rules but different cooperative structures. For one, there is just the group of friends with an authoritative host. For another, there is another box containing the game's creators and reasons exist to defer to their rules. If all the friends ultimately believe that "group fun" should drive their choices concerning how to interpret the rules of their game, then perhaps they agree theoretically at level four but have an applicative disagreement leading them to different reasons to use in choosing a decisionmaker. That is because they do not agree what a commitment to fun implies their choice of authoritative institution should be.

However deeply we reach into their modeling minds, we recognize, intuitively, that their cooperation will be, at some point, primitive. That it will be a matter of will, rather than logic. The normativity of the conditions of their game quite clearly does not arise somehow from the rules themselves. Nor does it spring from the concept of a "game." Their obligations to following the rules are no more and no less than their obligations to continue their cooperation. And that is, more or less, derivative of their felt obligations to one another, modified by the acceptability of defecting or the importance of collaborating in this instance of cooperation within their broader set of social project together. 


\section{ANSWERING THE Big QUESTIONS}

\section{A. A Summary Overview}

A model of a legal system is a set of information-exchanging institutions, each with one or more sets of reason trees. A reason tree, again, is a tree of secondary rules for the production of informational output given informational input. A participant $A$ believes participant $B$ has acted legitimately, when $A$ perceives $B$ 's actions to be consistent with a locally accepted model of the institution corresponding to their cooperative enterprise. That is, $A$ accepts $B$ 's judgment if it accords with a model of the institution that $A$ accepts, even if $A$ prefers another model of the institution that would reject $B$ 's particular judgment.

Importantly, $A$ 's judgment concerning the legitimacy of $B$ 's model depends on its fit with a model $A$ accepts $u$ nder the set of actual and imagined resolutions. $A$ may later find reason to reject the model he or she had accepted in cooperation with $B$ if facts arise, or are imagined as a realistic possibility, that call for an unacceptable judgment under that model. In such a case, the set of models acceptable to $A$ changes, and, in order to cooperate, $A$ and $B$ must identify another model of institutional behavior that they both accept.

For example, $A$ and $B$, Supreme Court justices, may each accept the model of their institution that identifies the controlling role of the Constitution, a set of acceptable (even if not preferred) interpretive methods to extract meaning from the Constitution, and, most basically, the principle of majoritarianism to identify the Court's institutional output, i.e., the majority opinion. Because they each accept this model, $A$ and $B$ cooperate despite theoretical disagreement at various levels arising from interpretive differences in any number of cases.

The fact of model acceptance is just that, a fact. It could be otherwise, and it does not follow from any other rule. But it is a social fact that does not preclude radical and theoretical disagreement about what the institution's output ought to be or even what more specific models ought to be used. Our discussion of reason trees illustrated the tiered complexity of models and the qualitatively different ways in which agreement can be reached and disagreement had. The acceptance of a basic model, the mental act equivalent to cooperation itself, represents agreement only about the validity of the output, not its correctness.

Such a basic model, if it is shared, is equivalent to Hart's rule of recognition - but at a local level, the level of the institution itself. A legal system, as a union of institutions, is a product of local existence criteria. An individual accepts a legal system, if he or she observes its functioning as consistent with 
a model of institutions and information that he or she accepts (for reasons ranging from enthusiastic agreement to fear-drenched coercion). A legal system exists if sufficient people accept models they believe describe the operation of institutions that cooperation continues.

\section{B. The Traditional Questions of Jurisprudence}

How does the theory of law as mental modeling comprehend the traditional, big questions of jurisprudence? While analysis of the theory's place within the field as to each of these questions would constitute a full work on its own, it may help to highlight the theory's more obvious answers. ${ }^{112}$

- Identity: According to what reasons is something called a law while another thing is not? What identifies something as law?

- Possibility: How is it possible to recognize something as a law without acknowledging something else as law that sanctions that recognition? If law is necessary to identify something as a law, we would seem to be either in an infinite regression of identity questions or unable to identify anything at all as law.

- Normativity: What are the criteria (a) for declaring a law good or bad and (b) for concluding that it ought to be obeyed?

- Morality: Is there an irreducibly moral component in the task of identifying something as law?

We might add one more to this list:

- Interpretation: If a datum is identified as "law," how should it be used by an institution that concludes the datum is relevant to a decision it undertakes?

The traditional approaches to jurisprudence have amounted to statements about what the essence of law is and arguments applying that essence to answer these basic questions. ${ }^{113}$ To speak very generally, these descriptions have amounted to pictures of law as:

\footnotetext{
112 The outline here has been heavily influenced, as has been much of my thought concerning positivism and its challengers, by Scott Shapiro. The nature of these basic questions about legal systems is well-covered in the opening chapters of his book. SHAPIRO, supra note 47, at 1-50.

${ }^{113}$ See Brian Tamanaha, Necessary and Universal Truths About Law?, 1-2 (June 2016) (collecting essentialist statements of the jurisprudential aim, including, for example: Joseph Raz, BETwEEN AUTHORITY AND INTERPRETATION 24-25 (2009); Jules Coleman, Incorporationism, Conventionality,
} 
1. the commands, backed by threats, of a sovereign that is habitually obeyed, ${ }^{114}$

2. the predictions concerning how courts will resolve disputes in future, hypothetical cases, ${ }^{115}$

3. a cascade of rules proceeding ultimately from a rule of recognition that is obeyed and faithfully applied by an influential subgroup as a matter of social practice, ${ }^{116}$

4. rules that all comply with some basic norm, ${ }^{117}$

5. those rules that are part of a system that meets certain moral requirements that are authoritative on grounds outside the control of any humans, 118

6. those rules that are part of a system that meets certain moral requirements that themselves can be discovered through a process of reasoning from axiomatic but human-derived conceptions of the good, ${ }^{119}$

7. those rules that are recognized by both the legal system and morality,

8. the product of enactments by various institutions, which enactments meet certain requirements of fit with what has come before within the same system and that do so in a way that can be acceptably judged as consistent with the system's political morality, ${ }^{120}$

9. the elaborations by various officers that are consistent with a preexisting social plan intended to resolve future problems and also consistent with the idea of social planning, ${ }^{121}$

10. and the commands of those with sufficient power to compel the actions of others, where those commands might appear to be justified

and the Practical Difference Thesis, 4 LEgAL THEORY 381, 393 n.4 (2009); Julie Dickson, EvaluATION AND LEGAL THEORY 18 (2001)).

${ }^{114}$ Austin, supra note 31.

${ }^{115}$ Holmes, supra note 13, at 457-60.

${ }^{116}$ HART, supra note 8, at 100-17.

${ }^{117}$ Hans KeLSEN, GenERAL THEORY OF LAW AND STATE 115 (1945).

118 Thomas Aquinas, Summa Theologiae, I-II, Q.95, A.II (Thomas Gilby ed., Cambridge Univ. Press 2006) ("E]very human law has just so much of the nature of law as is derived from the law of nature. But if in any point it deflects from the law of nature, it is no longer a law but a perversion of law.")

${ }^{119}$ While I have disaggregated three sorts of natural law claims, many natural law theorists embrace elements of each. See, e.g., Lon. L. Fuller, Positivism and Fidelity to Law - A Reply to Professor Hart, 71 HARV. L. REV. 630, 644-46 (1958); Finnis, supra note 16.

${ }^{120}$ DwORKIN, supra note 7 , at 254-58.

${ }^{121}$ SHAPIRO, supra note 15 , at 195-232. 
by principle but ultimately reflect the personal interests of the powerful (so that all law is no more than the technique by which the powerful hold on to power). ${ }^{122}$

What these understandings have in common is their striving to understand our social practice of lawmaking and dispute resolution as an integrated system. What are we doing when we do law? According to each of these conceptions, we act in systematic ways captured by the descriptions and criteria the model asserts. In sorting non-legal human interactions from legal ones, each of these theories has been designed to answer at least some of the basic questions. And each has been attacked for failing in ways large and small to do so.

My approach is different. I deny that there is a single model or concept of the law and instead assert that to do law is precisely to engage cooperatively in acts of modeling. Legal participants invoke models to make sense of and to reach judgments concerning their shared social enterprise, just as they do with other social and physical phenomena. Because of the complexity of the task, there is no single model that all participants in a legal system use in all instances. And because they have not reached agreement as to all actions that should be taken, they even disagree about whether particular models are correct, while ultimately accepting decisions at least consistent with acceptable models of greater generality.

"The Law" is therefore an illusion. There is only the participation in that portion of our perceived reality that we conceive, through mental modeling, as the practice of law. There is no Cathedral; there are only views of it. In this sense, law arises from the act of perceiving, not from a thing awaiting perception.

In this work, I have introduced a particular language, one of institutions connected by informational pathways, that describes generically the models people maintain about law. With that language, we can describe legal disagreements and legal practice in new and more insightful terms. It helps us to see how legal practice is the continual fashioning, querying, adopting, rejecting, accepting, and refashioning of information-institution models.

\footnotetext{
122 See Robert Gordon, Unfreezing Legal Reality: Critical Approaches to Law, 15 FLA. ST. U.L. REV. 195, 196-201 (1987); see also Lawrence B. Solum, On the Indeterminacy Crisis: Critiquing Critical Dogma, 54 U. CHI. L. REV. 463, 467-70 (1987) (describing, for the purpose of analysis, the "mystification thesis," "the view that legal rules mystify structures of domination").
} 


\section{Identity: According to what reasons is something called a law while another thing is not? What identifies something as law?}

The legal system is perceived by an individual as an identified model of institutions and their reason trees. An external identification, or a perception, of law is one's observation of a group that appears to be cooperating and maintaining mutual acceptance of models of their cooperation. A law within that legal system is shorthand for a particular datum or set of data identified as authoritative by an institution within one's model of the legal system.

The modeling understanding looks directly at structured thinking as it exists in the brain. It does not view law as a concept defined by essential properties. ${ }^{123}$ Of course, law as the actual human understanding of the conditions of cooperation, as the mutual efforts to know other minds, might be considered a sort of concept. Perhaps it could even be critiqued on the grounds Brian Tamanaha criticizes most analytical jurisprudence. He points to theorists' tendency to bootstrap concepts using pre-theoretical assumptions concerning what counts as law. As he puts it, "This method is circular: their assumptions about what is the paradigm of law determines the resulting theory of what law is, which is then applied to dictate what does and does not qualify as law for all places and times."

I do indeed rely on a pre-theoretical claim, that human beings recognize cooperation and decide whether to cooperate. Importantly, though, everything I argue is potentially as falsifiable as any other claim about human behavior. It is falsifiable not in the weak and circular sense that we can check whether the description captures historical systems we otherwise believe should be captured, but in the much stronger sense that investigations of cognition can support, alter, or disprove the manner in which I argue law is per-

\footnotetext{
${ }^{123}$ Compare my approach with an essentialist approach, one which seeks to establish necessary attributes to count as a legal system. Let $U$ be the set of all properties that social institutions might have. $\mathrm{L}$ be the set of all sets of properties corresponding to all instances we would like to call law. Let $\mathrm{C}$ be the intersection of all sets in $\mathrm{L}$. C is the set of those properties present in every legal system. Let $\mathrm{P}$ be the power set, or set of all possible subsets, of $\mathrm{C}$. Any member of $\mathrm{P}$ is a subset of properties present in all legal systems. Let $\mathrm{Q}$ be the subset of $\mathrm{P}$ so that no member of $\mathrm{Q}$ is a subset of any member of the set of all social institutions that is not in L. The claim that there is an a posteriori concept of law is the claim that Q is not empty - that there is a set of properties common to all legal systems that is possessed by no social institution that is not a legal system. The universalist claim, that all legal systems are defined by some essence is that $\mathrm{Q}$ has a single member. Note that $\mathrm{L}$ and $\mathrm{U}$ quite obviously depend on our observations and imaginations. There is no evidence that it is possible to identify a singleton Q no matter the U.

In contrast, my theory relies on a single property, called human cooperation, and recognizes a legal system with every instance of that property. The content of the legal system depends on the states of mind of the participants in that cooperation. My only pre-theoretical claim is that human cooperation can be identified by humans. Again, I realize this is open to critique as itself essentialist.

${ }^{124}$ See Tamanaha, supra note 113, at 21-22.
} 
ceived and judged. Whether one agrees that the cooperative systems described as they are by this theory should define law as a concept is a far less interesting question to me. I turn to the related concern that law and other cooperative systems may be distinguished by their normativity below.

Another sense of the identity question, though, is how we can predict the contents of what a cooperative group will call its "law." Our Monopoly players and the residents of a town within the jurisdiction of the town council are similarly situated from the point of view of the modeling theory. We have two cooperative groups, the laws of which are identified by the models its participants maintain. But, one might argue, there is something that causes ordinary people to call the latter system a system of laws and the former system a cooperative game with rules.

This criticism does not express skepticism of the underlying modeling mechanism. Rather, it urges better appreciation of the heterogeneity of attitudes a participant may have toward the variety of cooperative forms with which she has experience. Compared to a game among friends, a town's legal system may be more formal, more remote from the individual, less susceptible to change, or any number of other differences concerning content. But Brian Tamanaha has it exactly right: The only way to know whether a group of people considers a legal system in the model-theoretical sense to be a legal system in a cultural-linguistic sense similar to our own conventional notion is to ask or to study them. ${ }^{125}$ In other words, "law" can be distinguished from other forms of cooperation only by convention, only by how groups themselves in fact do distinguish such forms. If a particular cooperation is not viewed by its participants as "law" in the sense we usually use the term, it has nothing to do with the cooperation's modeled structure and everything to do with attitudes toward the cooperation itself. And those attitudes need not be homogeneous among participants. A member of the mafia may prioritize mob rules ahead of, and even feel them to be more authoritative and binding, than the law of the state or town in which the mobster lives.

\section{Possibility: How is it possible to recognize some- thing as a law without acknowledging something else as law that sanctions that recognition?}

The modeling theory, like Hart's theory, finds in acceptance the ultimate criterion of law. ${ }^{126}$ In particular, an individual accepts as law, from the internal point of view, those outputs consistent with a model of the legal system she accepts. This is a cognitive fact. Externally, we can describe the legal

\footnotetext{
${ }^{125} I d$. at 24-26 (noting that understanding a group's law as whatever the group conventionally identifies and treats as "law" is "not itself a concept of law but a conventionalist criterion for the identification of law"); see also note 10, supra.

${ }^{126}$ See Part III(D), supra.
} 
system of a cooperating group as its mutually accepted models. In degenerate cases, we can observe that there is fundamental disagreement, i.e., that there is no minimal mutual acceptance, but that cooperation is proceeding on account of mistakes concerning locally identified models.

\section{Normativity: What are the criteria (a) for declaring a law good or bad and (b) for concluding that it ought to be obeyed?}

A law is "bad" but obligatory, from an individual's point of view, if it is consistent with a locally accepted model but inconsistent with a locally preferred model. A law is not obligatory when it is inconsistent with an individual's locally accepted models. Law's normativity arises from the acceptance of cooperation and is nothing more than the "should" induced by the cooperating group.

Even if an individual concludes that a law is immoral (which is essentially to conclude that it is inconsistent with another model of human cooperation she maintains and that two cooperative regimes of which she is a part conflict), she might conclude that practical considerations require compliance. That fact, that compliance is justified by practicality, means that the individual accepts a model of the legal system with which the law complies. She may not prefer it, but she accepts it. ${ }^{127}$

Consider the famous gunman scenario. ${ }^{128}$ An assailant holds up a victim: "Your money or your life." That action, the gun, and the language bind the two participants together in an instance of human cooperation, even though it could hardly be further from a voluntary union. Even here there is law, and the gunman is making it. The victim accepts a locally identified model, the one in which the gunman may decide to kill him unless he complies with the gunman's orders. The statement, "Your money or your life," is consistent with the locally identified model of the legal system. And in fact the victim complies with the request precisely because it is consistent with the accepted model. The reasons he had for accepting this model are the reasons for acting in accordance with the law that emerges from it.

Critically, the victim's acceptance of the model was, as are all attitudes of acceptance toward any legal regime, contingent on anticipated input data and based on an understanding of the relations among them. If the gunman orders something the victim believes would be worse than death, the victim may not cooperate. So too if the victim discovered the gun was fake or if the

\footnotetext{
${ }^{127}$ Of course, practical considerations may be broader than the mere sanction prediction undertaken by a Holmesian bad man. Holmes, supra note 13, at 459. But the idea is close, and knowing a participant's reason for acceptance could give us insight into the limits of her acceptance in the future as new and unforeseen inputs must be processed.

${ }^{128}$ See HART, supra note 8, at 19-24.
} 
victim suddenly spied approaching police officers, these would affect the reasons the victim had for accepting the identified model of the assailant-victim legal system. The victim might now not accept an order of the gunman, because he has rejected the model of the system in which the gunman's orders are authoritative.

The gunman example illustrates my agreement with Scott Hershovitz that there is not a distinct "legal" domain of normativity. The victim in the above example of course does not have a special "gunman-victim law reason" to comply with the gunman's orders. Like Hershovitz, I believe that our reasons for following what we identify as law are not distinct from other reasons we have to cooperate. As he puts it: "Our social practices don't give rise to new kinds of normativity; rather they warrant new normative judgments of the old familiar kind. This is true even when the social practice in question involves positing rules." 129

Under the modeling understanding, our judgments concerning the ought-inducing effect of rules are completely parasitic on our attitudes toward the cooperation from which the rule structure is inseparable. Our Monopoly players' obligations not to cheat or disrupt are just those they have decided they owe one another in their cooperative enterprise, the ones owed with respect to that cooperation situated among other instances of cooperation among them. Their attitudes would surely be different had they come together not as friends but as competitors in a high-stakes monopoly tournament. ${ }^{130}$

Different instances of cooperation and their corresponding legal systems give rise to different model domains and yield different rules. One's reasons for following those rules coincide with the felt obligation to the other participants in that cooperation. This is why punishing rule violation is, essentially, active criticism of defection from the cooperation. It is not surprising that groups often try to assert that the reason for following their rules is deeply moral, ${ }^{131}$ basically to stretch the articulated purpose of the cooperative enterprise. If they succeed, they can claim that the reason to cooperate with them

\footnotetext{
${ }^{129}$ Hershovitz, supra note 46, at 1197.

${ }^{130}$ Hershovitz makes precisely this point using the example of competitive rather than friendly games of chess: "I said before that the FIDE rules improve play of the game, but that will only be true when the point of playing is to match wits in the fashion that the rules facilitate. If the point is simply to have fun, then appeals to the FIDE rules will almost certainly get in the way." Id. at 1183. The FIDE rules are "normative" only to the extent cooperating in the competition is normatively desirable, in which case the normative tug of the FIDE rules is of the more usual kind, urging us to cooperate when we have agreed to cooperate and wish to continue.

${ }^{131}$ See, e.g., Bowers v. Hardwick, 478 US 186, 197-99 (1986) (Powell, J., concurring) (defending Georgia's sodomy ban by arguing that "[t]o hold that the act of homosexual sodomy is somehow protected as a fundamental right would be to cast aside millennia of moral teaching"), overruled Lawrence v. Texas, 539 U.S. 558 (2003).
} 
is the same as the reason to be "good" more generally. With that framing, violation / defection can be criticized as defection from a more global system.

Similarly, civil disobedience is the intentional and publicized defection from a group, intended to highlight the severed connection between the legal rules of a system and the rules of some other system (religious or moral), both of which make claims on the group's members. Its purpose is to bring the legal rules into alignment with those of the other system. ${ }^{132}$

\section{Morality: Is there an irreducibly moral component in the task of identifying something as law?}

No, not in the sense that there are criteria that sort non-law-cooperation and law-cooperation. The deeper question is whether there is something about the entities that compose the legal system that inevitably, as an empirical matter, causes the use of one class of models to succeed and another class to fail. ${ }^{133}$ Must any successful legal system be consistent with models that have a common set of roots we could conventionally identify as "morality"?

Lon Fuller's story of the chaos of Imperium Rexum should prompt us to consider reasons that a fundamentally unfair manner of dealing out coercion will not be stable. ${ }^{134}$ Again, I do not think that instability or a lack of longevity negates the fact of the cooperative process while it exists. Unstable cooperation is still cooperation while it lasts. It is also obviously possible to accept a model of cooperation over which one has no control and into the finer details of which one has virtually no insight. The reasons for doing so almost certainly do not run deeply, and so such acceptance is likely to be thin.

It is worth noting, though, that Fuller's eight routes to the failure of a legal system all describe types of rulemaking that would be nearly impossible for a participant in the system to model. ${ }^{135}$ For Fuller, there is no law without a moral obligation of obedience, and that obligation attaches only if the eight

\footnotetext{
${ }^{132}$ See Martin Luther King, Jr., Letter from a Birmingham Jail (Apr. 16, 1963), reprinted in 26 U.C. DAVIS L. REV. 835, 841-42 (1993) ("I submit that an individual who breaks a law that conscience tells him is unjust, and who willingly accepts the penalty of imprisonment in order to arouse the conscience of the community over its injustice, is in reality expressing the highest respect for law.... [W] who engage in nonviolent direct action are not the creators of tension. We merely bring to the surface the hidden tension that is already alive. We bring it out in the open, where it can be seen and dealt with. Like a boil that can never be cured so long as it is covered up but must be opened with all its ugliness to the natural medicines of air and light, injustice must be exposed, with all the tension its exposure creates, to the light of human conscience and the air of national opinion before it can be cured.").

${ }^{133}$ This rationalized natural law, a minimal set of criteria for law to function, is evident in both the procedural minima of Fuller and of the norm-inseparability suggested by John Finnis, Law and What I Truly Should Decide, 48 AM. J. OF JURIS. 107, 107-15 (2003).

${ }^{134}$ See FULLER, supra note 16, at 33-41.

135 These routes are, roughly: secret or unpublicized rules, obscure and impossible to understand rules, retroactive rules, contradictory rules, rules that are physically impossible to comply with, rules that rapidly change, and a strong divergence between rules as adopted and as applied. Id.
} 
failures are negated and law attains, thusly, what he calls an "inner morality." "136 We might understand Fuller's principles of inner morality not as criteria for something ultimate, the view that invites appeal to more traditional understanding of natural law, but as the minimal conditions under which modeling in rule-understanding detail will become possible. If an individual cannot model the legal system at a level of generality that at least reaches statements of the rules that will apply to adjudicate behaviors within her realms of possibility, then she cannot locally accept such a model. And her cooperation, if it exists at all, will necessarily be at a level above the level of practical rules. In an act of ego death, she will accept a purely authoritarian model: that Rex decides based on reasons known only to him. Her acceptance will be only of the fact of Rex's authority. She may "remain[] faithful to him throughout his long and inept reign. [But she will not be] faithful to his law, for he never made any." 137 Indeed, she will not perceive any.

Again, whether she ought to comply with Rex's rule, whether we should call Rex's system a "legal system," these are matters of judgment and convention. The modeling theory makes it possible to distinguish from the model of an ordinary legal system an information-and-institutions model that consists of no reason trees that go deeper than authority submission. The mechanisms are the same. The labeling need not be.

What about the constraints of substantive morality? My model presupposes that law can be identified with institutional output and that characteristic of accepting that output as law is the acceptance of a model of law that includes that institution and a reason tree within it that is consistent with its output. Moral principles important to the group may not be announced by any particular institution. An individual may only observe lots of behavior consistent with them (though they may hear people talk about them, perhaps even articulating the rules that would form within a reason tree of someone acting consistently with them). Observing lots of consistent behavior is to observe convergent habits. This may, externally, allow us to predict what others are likely to do in the future and perhaps even modulate our own behavior to match the group's. But further, it may be possible to infer reason trees (to identify models) and thus to infer part of the group's code. Not acting consistently with such reasons could then create in other participants grounds for criticism, and, further, there may be institutions that use that moral principle in their reason trees and thus take legal actions (produce outputs) based on the individual's deviation. Knowing this, an individual identifies models of institutions within the group as containing these moral reasons, even if those reasons are nowhere stated.

${ }^{136}$ See, e.g., Fuller, supra note 119 , at 644-46.

${ }^{137}$ Id. at 41. 
The upshot of this complex process is that an outside observer, taking account of the multiplicity of legal relationships within the group, might have a hard time identifying the social facts, which arise from moral rules that have not been expressed, behind later treatment of defectors. But these outcomes may be an emergent property of a group whose members have internally identified and accepted models that are consistent with the moral principle they have seen followed by others and assume others have adopted.

\section{Interpretation: If a datum is identified as "law," how should it be used by an institution that concludes the datum is relevant?}

An institution interprets law when it identifies the reasoning of another institution and uses it to connect an input question to institutional output. When we say that an institution interprets a particular legal datum, we mean that it identifies a model of the legal system and a set of reasons arising from an institution within that model. The model the interpreting institution chooses and the institution or institutions it privileges within the model are justified, ultimately, by a level-four theory. Generically, an interpretation has the following form:

[source institution] $\rightarrow$ [output] $\rightarrow$ [interpreting institution] $\rightarrow$ [extraction of privileged institution's reasons] $\rightarrow$ [incorporation into interpreting institution's reason tree] $\rightarrow$ [use dispute input data and newly reformed reason tree to decide].

This general understanding of an interpretation takes many different forms. We see that a common law judge faced with the input data of disputing parties will attempt, following a level-three rule perceived at a level of complexity sufficient for the task, to identify and to interpret "controlling precedent." The source institution here, of course, would be prior courts.

Importantly, though, "interpretation" need not co-locate the data source and reason source. ${ }^{138}$ That is, the effort need not be to recover those of the source's reason trees that led to the dissemination of the information under consideration (an original intention endeavor). Let us consider this possibility more carefully in the context of statutory interpretation.

Ultimately, again, a judge applying a statute is concerned with the leveltwo reasons he or she should use to decide the case. If a statute applies, then we already have a model of the legal system in which the statute is a relevant datum. The critical point is that the statute itself is not a reason tree, but, if it

\footnotetext{
138 This way of speaking about the problem is compatible with Corey Yung's "complete constitutional communication model," which account for pretext, subtext, and later precedent. Yung, supra note 86, at 332. Mine is a more institution-based approach, associating each source of data with a modeled institution.
} 
is relevant, it must be translated into one. Ultimately, the question is how we should convert textual data into reasons for decisions. We have multiple options, and, critically, they are distinguished by the model of the legal system the deciding institution applies. Perhaps the statute is a datum that chiefly functions to aid the court in identifying the set of data it needs to reconstruct the reason tree of the institution that created the datum.

Perhaps one's level-four reasons for recognizing the salience of this datum and its author point to the datum-creator's authority running only so far as to control the sets of data it conveys to a truly authoritative institution, i.e., the one identified by the level-four theory as possessing the reason trees we seek to recover. For instance, suppose our theory demands that while the legislating body has the authority to choose the data to transmit, the meaning of those data and the reasons we are trying to recover are determined by the audience for the data, not its source.

Under this theory, it is the job of the interpreting institution to recover the reasons as they would be found by that authoritative institution, the audience, given the datum-creator's act of creation. If the authoritative institution is a broad subset of the public as it existed and processed information at the instant of the creation, then this model is an abstract public-meaning originalism. Already, we have a far more complex information-and-institutions model of the system than the simple sender to receiver model.

Recognizing, though, that we lack access to information concerning the audience's reasons, we might further refine our model, assuming that it was equivalent to a generic audience that processed information in predictable ways. Perhaps its processing can be sufficiently approximated by assuming it would translate words into reasons by passing the text through contemporary dictionaries and resolving ambiguities according to a set of fixed rules. This is originalist-oriented textualism, justified by the same level-four theory that led to public-meaning originalism. The basic move is to replace the ineffable but actual reason trees of the mass public with the interpretive equivalent of the rational actor model. That is, we replace impossibly complex collections of trees with a simple and linear program of text-to-reason mapping. ${ }^{139}$

Canons are therefore models of institutional reasoning meant reasonably to approximate human interpretation, the rational interpreter model. One hope of those who embrace this theory is that if courts publicize that they will use such canons and dictionaries, then the data-producing institution and the

\footnotetext{
${ }^{139}$ If we are fully invested in the authority of "the People" and are using approximation tools to realize it, then we are also trying to recover that institution's level-four conclusions. Those conclusions concern its views concerning what motivations and information sources are relevant to its interpreting the information for which it is the audience.
} 
public that holds that institution accountable will act accordingly. And so even if the model it announces is false for existing data, in that it identifies with those existing data reasons that no modeled institution actually had, the canons-and-dictionary choice might dynamically grant the theorized authority to those institutions. ${ }^{140}$

All this suggests that an interpretation of a datum is a function of (a) a model of the legal system, (b) a choice of time at which the model is queried, (c) a level three choice concerning the institution whose reason resulting from the datum will be adopted, and (d) a model of that institution's reasons given the datum, meaning, in particular, a posited function that would map the datum to a reason that can then be adopted as the interpreting institution's own or can, at least, alter the interpreting institution's reasons. Interpretative disagreement within a legal system is not a single disagreement over a uni-dimensional array of methods but a multi-dimensional one, involving time, institutional choice, and approximation.

\section{Evaluation}

Reflecting on the generality of the experience of cooperation, one may naturally begin to wonder about the outer limits of law. If using "law" this way sweeps in too much of our experience of the universe, I would be open to the charge that I have charted nothing useful here, nothing distinctive about what is really going on when a court hands down a decision or a legislature passes a statute. But I think the move toward this theory's brand of generalization and demarcation is critical precisely because it shows just how much of our experience with the law that we label as such, the law we say we have, is a product of mental categorization consistent with a narrative about authority and constraint that could be otherwise. Our perceptions are perceptions. They gain power when they are shared.

But what makes mine the right or at least a useful perspective? Ultimately, we are trying to get to know the practices of human beings better. "What is a human being? Legal theorists, perforce, must answer this question: jurisprudence, after all, is about human beings." ${ }^{141}$ The simple answer to that question, however, is that we do not yet know. While a descriptive theory of law grounded in posited individualized models of institutions, information, and rules helps to explain divergent legal opinions and practices, there is more research to do.

\footnotetext{
${ }^{140}$ See, e.g., Alexander v. Sandoival, 532 U.S. 275, 287-91 (2001) (refusing, when deciding whether a statute crteated an implied private right of action to look outside statutory text for indicia of congressional intent because the Court "found no evidence anywhere in the text to suggest that Congress intended to create a private right").

${ }^{141}$ Robin West, Jurisprudence and Gender, 55 U. CHI. L. REV. 1, 1 (1988).
} 
As a matter of legal theory, I have suggested a language for the mental models we construct of legal practice. And I identify criteria, based on individual judgments concerning such models, for identifying a legal system and for distinguishing a system's laws from things that are not its laws. I believe this understanding of law as modeling is "correct" at the very least in the sense that it usefully explains our intuitions of legal phenomena and that it explains both legal agreement and theoretical disagreement. Following the lead of Brian Leiter, who borrows from the literature on theory choice in the sciences, we could identify for theories three desiderata: simplicity, comprehensiveness, and conservatism. Succinctly: theories that explain more phenomena, more simply, and with minimal damage to other "well-confirmed theories" are preferable. ${ }^{142}$ The modeling theory excels in each respect, (a) giving a standardized account of ordinary intuitions concerning how institutions are constituted and connected and (b) adding a theory of agreement and acceptance to explain longstanding jurisprudential puzzles. And it does all this while illuminating why other approaches have explanatory power and theoretical attraction. At its core, the theory gives a simple account of the law in our heads.

\section{CONCLUSION}

Roscoe Pound famously distinguished between the law in the books and the law in action. ${ }^{143}$ The former is the collection of writings of legislatures and courts, somehow ordered by the writings themselves. This understanding is law as the rule book. The latter point of view recognizes that law is active, that it is the actual experience of authority that the criminal defendant undergoes, ${ }^{144}$ the unfolding deployment of reasons to justify orders. And while the past writings of institutions will be cited as composing those reasons, the doing of law is underdetermined by them.

But neither is law to be found in objective description of behaviors. The law is not equivalent to a documentary film. It is more than the fact of action, just as it is more than books. There is also the law in the head. This, as we have seen, is where the consciousness of human beings and the inevitable conditions people impose on their mutual cooperations transform underdetermined, contradictory, and vague writing or utterance into the fact of action. ${ }^{145}$ The real law arises from the ever-changing potential of a congregation of

\footnotetext{
142 Brian Leiter, Explaining Theoretical Disagreement, 76 U. CHI. L. REV. 1215, 1239 (2009).

${ }^{143}$ Roscoe Pound, Law in Books and Law in Action, 44 AM. L. REv. 12 (1910).

${ }^{144} I d$. at $16-19$.

${ }^{145}$ See supra note 38 and accompanying text (quoting and discussing Robert Cover's theory of interpretation as bonded word and deed).
} 
minds. And for jurisprudence to advance, it must turn to asking and answering questions about how human minds understand legal actions, form legal reasons, and transform those reasons into new actions.

- Do jurors and judges use similar types of models to resolve factual conflicts or to understand legal rules?

- Are opinions about legal rules formed by simulating applications of the law and responding to the results affectively?

- If so, are such simulations run with particular actors in institutional roles and particular actors as victims, defendants, and plaintiffs?

- Do these answers depend on experience, so that lawyers and judges use a more conceptual brand of processing than does the public? ${ }^{146}$

It may be that since at least the time of Holmes the lawyer of the future has been the lawyer of statistics and economics, ${ }^{147}$ but the student of law has always been and will always be a student of us. Perhaps we are ready to move beyond introspection and dialogue to approach this study. Brain activation research could be a next step to understanding how minds reach decisions through simplification of their physical and social worlds.

A common language and set of starting points, as I have laid out here, can help to identify legal disagreements for what they often are: different understandings of how things are supposed to work. We perceive law differently, between one another and even within ourselves from moment to moment. And yet we continue to cooperate. In seeking to understand this cooperation, we err when we attempt to capture its essence in an abstract rule that, as a matter of logic, circularly defines what it defines. In the end, we must never forget that it is a dynamic interaction of minds we are expounding.

\footnotetext{
146 This hypothesis, that there are two such modes of cognition, is suggested by some cognitive scientists. See Piotr Winkielman et al., Embodiment of cognition and emotion, in APA HANDBOOK OF Personality and Social Psychology, Volume 1: Attitudes and Social Cognition 151-175 (2014) (They hypothesize that "novel concepts are initially grounded in an embodied metaphor. However, if a metaphor is reused often enough, and the results of its use can be represented well by a semantic network, then semantic processing will be an efficient shortcut, eliminating the need for simulation.").

${ }^{147}$ Holmes, supra note 13, at 469.
} 